\title{
Effects of specimen size and shape on compressive and tensile strengths of self- compacting concrete with or without fibres
}

\section{Farhad Aslani}

Centre for Built Infrastructure Research, School of Civil and Environmental

Engineering, University of Technology Sydney, Australia

Self-compacting concrete (SCC) can be placed and compacted under its own weight. Modifications in the mix design of SCC may significantly influence the material's mechanical properties. Therefore, it is vital to investigate whether all the assumed hypotheses about conventional concrete also hold true for SCC structures. This paper discusses an experimental programme that was carried out to study the effects of specimen size and shape on the compressive and tensile strength of SCC and fibre reinforced SCC. For this purpose, cube specimens with 100 and $150 \mathrm{~mm}$ dimensions and cylinder specimens with $100 \times 200$ and $150 \times 300 \mathrm{~mm}$ dimensions were casted. The experimental programme examined four SCC mixtures: plain SCC, and steel-, polypropylene- and hybrid-fibre reinforced SCC. Compressive and tensile strengths were tested after 3, 7, 14, 28 and 56 days. The paper also investigates correlations between compressive and tensile strengths and the size and shape of the specimen.

\section{Notation}

$B \quad$ empirical constant

$d \quad$ diameter of cylinder specimen: $\mathrm{cm}$

$d_{\mathrm{a}} \quad$ maximum aggregate size: $\mathrm{mm}$

$f_{\mathrm{c}}^{\prime} \quad \mathrm{N}-\mathrm{SCC}$ mix compressive strength: MPa

$f_{\mathrm{cDS}}^{\prime} \quad$ DS-SCC mix compressive strength: MPa

$f_{\mathrm{cfD}}^{\prime} \quad \mathrm{D}-\mathrm{SCC}$ mix compressive strength: $\mathrm{MPa}$

$f_{\text {cmy }}^{\prime}(d)$ compressive strength with size of general cylinder: MPa

$f_{\text {ct }} \quad$ N-SCC mix tensile strength: MPa

$f_{\text {cfS }}^{\prime} \quad$ S-SCC mix compressive strength: $\mathrm{MPa}$

$f_{\text {cmu }}^{\prime}(d)$ compressive strength of cube: MPa

$f_{\text {ctmy }}(d)$ tensile strength of cylinder: $\mathrm{MPa}$

$f_{\text {fctD }} \quad$ D-SCC mix tensile strength: $\mathrm{MPa}$

$f_{\text {fctDS }} \quad$ DS-SCC mix tensile strength: $\mathrm{MPa}$

$f_{\text {fcts }} \quad$ S-SCC mix tensile strength: MPa

$h \quad$ height of cylinder specimen: $\mathrm{cm}$

$l_{0} \quad$ width of crack band: $\mathrm{mm}$

$l_{\mathrm{f}} / d_{\mathrm{f}} \quad$ aspect ratio

R. I. fibre reinforcing index

$V_{\mathrm{f}} \quad$ fibre volume fractions

$\alpha \quad$ empirical constant

$\lambda_{0} \quad$ empirical constant

$\sigma_{\mathrm{N}}(d) \quad$ nominal strength: $\mathrm{MPa}$

\section{Introduction}

In the last three decades, there have been significant improvements in concrete technology, and these improvements have led to the development of high-performing concrete, such as selfcompacting concrete (SCC). SCC is a highly workable, nonsegregating concrete that can easily reach remote corners, fill congested formworks and provide reinforcement without any vibration efforts. For the past two decades, SCC has been mainly used for bridges, and for underwater and heavily reinforced concrete structures. In the recent years, however, the use of SCC has been extended to building construction (Okamura, 1997).

SCC consists of the same components as conventional concrete (CC) cement, water, aggregates, admixtures, and mineral additions, but the final composition of the mixture and its fresh characteristics are different. Compared with $\mathrm{CC}$, SCC contains larger quantities of mineral fillers such as finely crushed limestone or fly ash, as well as higher quantities of high-range waterreducing admixtures, and the maximum size of the coarse aggregate is smaller. These modifications in the composition of the mixture affect the properties of the concrete in its hardened state. Also, fresh properties and properties during hardening (e.g. hydration process) are influenced by the modifications in the composition. Using SCC can result in labour and cost savings, 
but the increasing application of SCC requires a more precise understanding of its behaviour and performance. It is crucial to estimate the mechanical properties of this structural material accurately. The compressive and tensile strength of concrete is considered the most basic and important material property in designing concrete structures (Aslani and Nejadi, 2012a, 2012b, 2012c, 2012d).

The incorporation of fibres improves engineering performance of structural and non-structural concrete. The use of fibre-reinforced concrete (FRC) is also of special interest for retrofit and seismic design. The incorporation of metallic fibres can be problematic on some situations, especially when the fibre volume is high and the FRC is cast in sections with a moderate-to-high degree of reinforcement. The fibre content, length, aspect ratio and shape play an important role in controlling workability of FRC. Such concrete presents greater difficulty in handling, and requires more deliberate planning and workmanship than established concrete construction procedures. The additional compaction effort required for such concrete contributes to the increase in construction cost. In order to provide sufficient compaction, improve fibre dispersion, and reduce the risk of entrapping voids, the FRC is often proportioned to be fluid enough to reduce the need for vibration consolidation and facilitate placement. An extension of this approach can involve the use of SCC to eliminate, or greatly reduce, the need for vibration and further facilitate placement. A truly fibre-reinforced self-compacting concrete (FRSCC) should spread into place under its own weight and achieve consolidation without internal or external vibration, ensure proper dispersion of fibres, and undergo minimum entrapment of air voids and loss of homogeneity until hardening. Lack of proper self-compaction or intentional vibration and compaction can result in macro- and micro-structural defects that can affect mechanical performance and durability (Aslani and Nejadi, 2012e; Khayat and Roussel, 1999).

A few studies have been carried out on optimisation of the mix proportion for the addition of steel or polypropylene fibres to SCC. Meanwhile, there is insufficient research on the mechanical properties of FRSCC. In mechanical terms, the greatest disadvantage of cementitious material is its vulnerability to cracking, which generally occurs at an early age in concrete structures or members. Cracking may potentially reduce the lifetime of concrete structures and cause serious durability and serviceability problems. The addition of fibres into SCC mixtures has been studied by a number of researchers.

The standard concrete cylinders' $(150 \times 300 \mathrm{~mm})$ compressive strength is regarded for design purposes as the basic material property. However, the common concept is that the concrete compressive strength value is incorrect because the compressive strength of concrete changes based on the specimen's size and shape. The size and shape of test specimens used to determine the compressive strength of concrete differ from country to country; nevertheless, the most commonly used specimens are cylinders and cubes. Cylinders $(150 \times 300 \mathrm{~mm})$ are used in the USA, South Korea, France, Canada and Australia, among others, whereas cubes $(150 \mathrm{~mm})$ are the standard specimens used in the UK, Germany and most other European countries. Several countries (e.g. Norway) perform tests on both cylinders and cubes. Owing to differences in the shape and size, cylinder and cube strengths obtained from the same batch of concrete can differ (Yi et al., 2006). Cubes usually have a higher strength than cylinders.

Since the early 1900s, many studies (Aïtcin et al., 1994; Carrasquillo et al., 1981; Chin et al., 1997; Date and Schnormeier, 1981; Day and Haque, 1993; Lessard et al., 1993; Malhotra, 1976; Moreno, 1990; Nasser and Kenyon, 1984; Neville, 1995; Sleiman et al., 2000; Tokyay and Özdemir, 1997) in this field have been carried out. Most researchers have focused on developing guidelines for converting the compressive strength of concrete determined from nonstandard specimens to that of standard specimens. Many studies also investigated the relationship between cylinder strength and cube strength for CC. Generally, a factor of 1.2 is used to convert cylinder strength to cube strength for $\mathrm{CC}$. However, the factor gradually decreases as the concrete strength increases. The CEB-FIP code 1990 (CEB-FIP, 1993) also indicates that the ratio of the cube strength to cylinder strength with increasing compressive strength of concrete decreases progressively from 1.25 to $1 \cdot 12$. The ratios 1.25 and 1.12 correspond to cylinder compressive strengths of 40 and $80 \mathrm{MPa}$, respectively.

In this study, the effect of specimen sizes and specimen shapes on compressive and tensile strengths of SCC specimens with and without fibres is experimentally investigated based on fracture mechanics. Also, it postulates the relationship for the prediction of compressive and tensile strengths based on specimen size. Furthermore, to obtain the concrete compressive strength of cylinders from specimens of other shapes, it theorises relationships generally applicable to both specimen shapes (i.e. cylinders and cubes). Developing a formula for converting the strength of cubes into the strength of cylinders could be of considerable interest to designers.

\section{Experimental study}

The experimental programme consisted of 30 cube specimens with 100 and $150 \mathrm{~mm}$ dimensions, and 30 cylinder specimens with $100 \times 200 \mathrm{~mm}$ and $150 \times 300 \mathrm{~mm}$ dimensions. Also, it examined four SCC mixtures: plain SCC, and steel-, polypropylene- and hybrid-fibre reinforced SCC. Compressive and tensile strengths were tested after 3, 7, 14, 28 and 56 days.

\section{Properties of materials used in SCC and FRSCC Cement}

In this experimental study, shrinkage limited cement (SLC) corresponding to the AS 3972 (SA, 2010) standard was used. SLC is manufactured from specially prepared Portland cement clinker and gypsum. It may contain up to $5 \%$ of AS 3972- 
approved additions. The chemical, physical and mechanical properties of the cement used in the experiments are shown in Table 1. The chemical, physical and mechanical properties adhere to the limiting value or permissible limits specified in AS 2350.2, $3,4,5,8$ and 11 (SA, 2006).

\section{Fly ash}

It is important to increase the amount of paste in SCC because fly ash is an agent that carries the aggregates. As a consequence, eraring fly ash (EFA) has been used to increase the amount of paste. EFA is a natural pozzolan. It is a fine cream/grey powder that is low in lime content. However, in its finely divided form and in the presence of moisture it will react chemically with calcium hydroxide (e.g. from lime or cement hydration) at ordinary temperatures to form insoluble compounds possessing cementitious properties. The chemical and physical properties of EFA used in the experimental study are given in Table 2. The chemical, physical and mechanical properties of the EFA used adhere to the limiting value or permissible limits specified in AS 2350.2 (SA, 2006), AS 3583.1, 2, 3, 5, 6, 12 and 13 (SA, 1998).

\section{Ground granulated blast furnace slag}

Ground granulated blast furnace slag (GGBFS) is another supplementary cementitious material that is used in combination with SLC. GGBFS used in the experiment originated in Boral, Sydney, and it conformed to AS 3582.2 (SA, 2001) specifications. The chemical and physical properties of GGBFS are given in Table 3.

$\begin{array}{lc}\text { Chemical properties } & \\ \text { Calcium oxide } & 64 \cdot 5 \% \\ \text { Silicon dioxide } & 19 \cdot 3 \% \\ \text { Aluminium oxide } & 5 \cdot 2 \% \\ \text { Iron (III) oxide } & 2 \cdot 9 \% \\ \text { Magnesium oxide } & 1 \cdot 1 \% \\ \text { Sulfur trioxide } & 2 \cdot 9 \% \\ \text { Potassium oxide } & 0 \cdot 56 \% \\ \text { Sodium oxide } & <0 \cdot 01 \% \\ \text { Chloride ion } & 0 \cdot 02 \% \\ \text { Loss on ignition } & 2 \cdot 8 \% \\ \text { Physical properties } & \\ \text { Autoclave expansion } & 0 \cdot 05 \% \\ \text { Fineness index } & 405 \mathrm{~m} / \mathrm{kg} \\ \text { Mechanical properties } & \\ \text { Initial setting time } & 90 \mathrm{~min} \\ \text { Final setting time } & 135 \mathrm{~min} \\ \text { Soundness } & 1 \cdot 0 \mathrm{~mm} \\ \text { Drying shrinkage } & 590 \mu \mathrm{strain} \\ f_{c}^{\prime}(3 \text { days) } & 37 \cdot 2 \mathrm{MPa} \\ f_{c}^{\prime}(7 \text { days) } & 47 \cdot 3 \mathrm{MPa} \\ f_{c}^{\prime} \text { (28 days) } & 60 \cdot 8 \mathrm{MPa}\end{array}$

Table 1. Properties of cement

$\begin{array}{lc}\text { Chemical properties } & \\ \text { Aluminium oxide } & 26 \cdot 40 \% \\ \text { Calcium oxide } & 2 \cdot 40 \% \\ \text { Iron (III) oxide } & 3 \cdot 20 \% \\ \text { Potassium oxide } & 1 \cdot 55 \% \\ \text { Magnesium oxide } & 0 \cdot 60 \% \\ \text { Manganese oxide } & <0 \cdot 1 \% \\ \text { Sodium oxide } & 0 \cdot 47 \% \\ \text { Phosphorus pentoxide } & 0 \cdot 20 \% \\ \text { Silicon dioxide } & 61 \cdot 40 \% \\ \text { Sulfur trioxide } & 0 \cdot 20 \% \\ \text { Strontium oxide } & <0 \cdot 1 \% \\ \text { Titanium oxide } & 1 \cdot 00 \% \\ \text { Physical properties } & \\ \text { Moisture } & <0 \cdot 1 \% \\ \text { Fineness } 45 \text { micron } & 78 \% \mathrm{passed} \\ \text { Loss on ignition } & 2 \cdot 30 \% \\ \text { Sulfuric anhydride } & 0 \cdot 20 \% \\ \text { Alkali content } & 0 \cdot 50 \% \\ \text { Chloride ion } & <0 \cdot 001 \% \\ \text { Relative density } & 2 \cdot 02 \% \\ \text { Relative water requirement } & 97 \% \\ \text { Relative strength } 28 \text { days } & 88 \%\end{array}$

Table 2. Properties of fly ash

\section{Aggregate}

In this study, crushed volcanic rock (i.e. latite) coarse aggregate was used with a maximum aggregate size of $10 \mathrm{~mm}$. Nepean river gravel with a maximum size of $5 \mathrm{~mm}$ and Kurnell natural river sand fine aggregates were also used. The sampling and testing of aggregates were carried out in accordance with AS 1141 (SA, 2011) and the Regional Transportation Authority (RTA, 2006), and the results for coarse and fine aggregates are shown in Tables $4-6$ respectively.

$\begin{array}{lr}\text { Chemical properties } & \\ \text { Aluminium oxide } & 14 \cdot 30 \% \\ \text { Iron (III) oxide } & 1 \cdot 20 \% \\ \text { Magnesium oxide } & 5 \cdot 40 \% \\ \text { Manganese oxide } & 1 \cdot 50 \% \\ \text { Sulfur trioxide } & 0 \cdot 20 \% \\ \text { Chloride ion } & 0 \cdot 01 \% \\ \text { Insoluble residue } & 0 \cdot 50 \% \\ \text { Loss on ignition } & -1 \cdot 10 \% \\ \text { Physical properties } & \\ \text { Fineness index } & 435 \mathrm{~m}^{2} / \mathrm{kg}\end{array}$

Table 3. Properties of ground granulated blast furnace slag 


\begin{tabular}{|c|c|}
\hline Characteristics & Results \\
\hline Sieve size & Passing (\%) \\
\hline $13 \cdot 2 \mathrm{~mm}$ & 100 \\
\hline $9 \cdot 5 \mathrm{~mm}$ & 89 \\
\hline $6.7 \mathrm{~mm}$ & 40 \\
\hline $4.75 \mathrm{~mm}$ & 7 \\
\hline $2 \cdot 36 \mathrm{~mm}$ & 1 \\
\hline $1 \cdot 18 \mathrm{~mm}$ & 1 \\
\hline Material finer than 75 micron: \% & 1 \\
\hline \multicolumn{2}{|l|}{ Misshapen particles: \% } \\
\hline Ratio 2:1 & 13 \\
\hline Ratio 3:1 & 1 \\
\hline Flakiness index: \% & 20 \\
\hline Uncompacted bulk density: $t / m^{3}$ & $1 \cdot 36$ \\
\hline Compacted bulk density: $\mathrm{t} / \mathrm{m}^{3}$ & $1 \cdot 54$ \\
\hline Moisture condition of the aggregate: \% & $1 \cdot 3$ \\
\hline Particle density (dry): $\mathrm{t} / \mathrm{m}^{3}$ & $2 \cdot 65$ \\
\hline Particle density (SSD): $t / \mathrm{m}^{3}$ & $2 \cdot 70$ \\
\hline Apparent particle density: $t / \mathrm{m}^{3}$ & $2 \cdot 79$ \\
\hline Water absorption: \% & 1.9 \\
\hline Ave. dry strength: kN & 391 \\
\hline Ave. wet strength: kN & 293 \\
\hline Wet/dry strength variation: \% & 25 \\
\hline Test fraction: $\mathrm{mm}$ & $-9 \cdot 5+6 \cdot 7$ \\
\hline The amount of significant breakdown: \% & $<0.2$ \\
\hline \multicolumn{2}{|l|}{$\begin{array}{l}\text { The size of testing cylinder }=150 \mathrm{~mm} \\
\text { diam. }\end{array}$} \\
\hline Los Angeles value grd. 'K': \%loss & 13 \\
\hline
\end{tabular}

SSD: saturated-surface-dry.

Table 4. Properties of crushed latite volcanic rock coarse aggregate

\section{Admixtures}

The superplasticiser, viscosity-modifying admixture, and highrange water-reducing agent admixture were used in this study. The new superplasticiser generation Glenium 27 complies with AS 1478.1 (SA, 2000) type high range water reducer (HRWR) and ASTM C494 (ASTM, 2000) types A and F are used. The Rheomac VMA 362 viscosity modifying admixture that was used in this study is a ready-to-use, liquid admixture that is specially developed for producing concrete with enhanced viscosity and controlled rheological properties. Pozzolith 80 was used as a HRWR agent admixture in the mixes. It reduces the quantity of water required to produce concrete of a given consistency, with greater economy, of a given strength. It meets and exceeds AS 1478 (SA, 2000) type WRRe requirements for admixtures.

\section{Fibres}

In this study, two commercially available fibres, Dramix RC-80/ 60-BN type steel fibres and Synmix 65 type polypropylene (PP)

\begin{tabular}{|c|c|}
\hline Characteristics & Results \\
\hline Sieve size & Passing (\%) \\
\hline $6.7 \mathrm{~mm}$ & 100 \\
\hline $4.75 \mathrm{~mm}$ & 99 \\
\hline $2 \cdot 36 \mathrm{~mm}$ & 83 \\
\hline $1 \cdot 18 \mathrm{~mm}$ & 64 \\
\hline 600 micron & 42 \\
\hline 425 micron & 28 \\
\hline 300 micron & 19 \\
\hline 150 micron & 8 \\
\hline Material finer than 75 micron: \% & 3 \\
\hline Uncompacted bulk density: $t / m^{3}$ & $1 \cdot 52$ \\
\hline Compacted bulk density: $t / m^{3}$ & 1.64 \\
\hline Particle density (dry): t/m³ & $2 \cdot 58$ \\
\hline Particle density (SSD): $t / \mathrm{m}^{3}$ & $2 \cdot 60$ \\
\hline Apparent particle density: $t / \mathrm{m}^{3}$ & 2.63 \\
\hline Water absorption: \% & 0.7 \\
\hline Silt content: \% & 7 \\
\hline Degradation factor of fine aggregate & 90 \\
\hline \multirow{2}{*}{\multicolumn{2}{|c|}{ The wash water after using permitted }} \\
\hline & \\
\hline Moisture content: \% & $5 \cdot 5$ \\
\hline \multicolumn{2}{|l|}{ Method of determining voids content } \\
\hline$\%$ voids & 41.7 \\
\hline The mean flow time: $\mathrm{s}$ & $26 \cdot 5$ \\
\hline
\end{tabular}

SSD: saturated-surface-dry.

Table 5. Properties of Nepean river gravel fine aggregate

\begin{tabular}{lc}
\hline Characteristics & Results \\
\hline Sieve size & Passing (\%) \\
$1.18 \mathrm{~mm}$ & 100 \\
600 micron & 98 \\
425 micron & 87 \\
300 micron & 46 \\
150 micron & 1 \\
Material finer than 75 micron in aggregate & Nil \\
by washing: \% & \\
Uncompacted bulk density: $t / \mathrm{m}^{3}$ & $1 \cdot 39$ \\
Compacted bulk density: $\mathrm{t} / \mathrm{m}^{3}$ & $1 \cdot 54$ \\
Particle density (dry): $\mathrm{t} / \mathrm{m}^{3}$ & $2 \cdot 58$ \\
Particle density (SSD): $/ \mathrm{m}^{3}$ & $2 \cdot 59$ \\
Apparent particle density: $\mathrm{t} / \mathrm{m}^{3}$ & $2 \cdot 62$ \\
Water absorption: \% & 0.6 \\
Silt content: \% & 4 \\
\hline
\end{tabular}

SSD: saturated-surface-dry.

Table 6. Properties of Kurnell natural river sand fine aggregate 
fibres, were used. The mechanical, elastic and surface structure properties of the steel and PP fibres are summarised in Table 7.

\section{Mixture proportions}

One control SCC mixture (N-SCC) and three fibre-reinforced SCC mixtures were used in this study. The fibre-reinforced SCC mixtures contained steel (D-SCC), PP (S-SCC), and hybrid $($ steel + PP) $($ DS-SCC) fibres. The content proportions of these mixtures are given in Table 8. These contents were chosen to attempt to keep compressive strength to a level applicable to construction.

\section{Sample preparation and curing conditions}

The dimensions and shapes used in the experiments for compressive strength are 30 cube specimens with 100 and $150 \mathrm{~mm}$ dimensions, and 30 cylinder specimens with $100 \times 200 \mathrm{~mm}$ and $150 \times 300 \mathrm{~mm}$ dimensions. Also, cylinder specimens with $100 \times 200 \mathrm{~mm}$ and $150 \times 300 \mathrm{~mm}$ dimensions were used for splitting tensile tests. The specimens were prepared by directly pouring concrete into moulds without compaction. The specimens were kept covered in a controlled chamber at $20 \pm 2^{\circ} \mathrm{C}$ for $24 \mathrm{~h}$ until their demoulding. Thereafter, the specimens were placed in water presaturated with lime at $20^{\circ} \mathrm{C}$. The compressive and tensile strengths were tested after 3, 7, 14, 28 and 56 days.

\section{Properties of fresh concrete}

The experiments required for the SCC are generally carried out worldwide under laboratory conditions. These experiments test the flowability, segregation, placement, and compacting of fresh concrete. Conventional workability experiments are not sufficient for the evaluation of SCC. Some of the experiment methods developed to measure the flowability, segregation, placement and compaction of SCC are defined in the European guidelines (EFNARC, 2005) and ACI 237R-07 (ACI, 2007) for SCC, including specification, production and use as slump-flow, V-funnel, U-box, L-box and fill-box tests.

\begin{tabular}{|c|c|c|c|c|c|c|c|c|c|}
\hline Fibre type & Fibre name & $\begin{array}{l}\text { Density: } \\
\mathrm{kg} / \mathrm{m}^{3}\end{array}$ & $\begin{array}{l}\text { Length }(/) \text { : } \\
\mathrm{mm}\end{array}$ & $\begin{array}{l}\text { Diameter } \\
(d): \mathrm{mm}\end{array}$ & $\begin{array}{c}\text { Aspect } \\
\text { ratio } \\
(I / d)\end{array}$ & $\begin{array}{c}\text { Tensile } \\
\text { strength: } \\
\text { MPa }\end{array}$ & $\begin{array}{c}\text { Modulus of } \\
\text { elasticity: } \\
\text { GPa }\end{array}$ & $\begin{array}{l}\text { Cross-section } \\
\text { form }\end{array}$ & $\begin{array}{l}\text { Surface } \\
\text { structure }\end{array}$ \\
\hline Steel & $\begin{array}{l}\text { Dramix } \\
\text { RC-80/60-BN }\end{array}$ & 7850 & 60 & 0.75 & $80 \cdot 0$ & 1050 & 200 & Circular & Hooked end \\
\hline Polypropylene & Synmix 65 & 905 & 65 & 0.85 & $76 \cdot 5$ & 250 & 3 & Square & Rough \\
\hline
\end{tabular}

Table 7. The physical and mechanical properties of fibres

\begin{tabular}{|c|c|c|c|c|}
\hline Constituents & $\mathrm{N}-\mathrm{SCC}$ & D-SCC & S-SCC & DS-SCC \\
\hline Cement: $\mathrm{kg} / \mathrm{m}^{3}$ & 160 & 160 & 160 & 160 \\
\hline Fly ash: $\mathrm{kg} / \mathrm{m}^{3}$ & 130 & 130 & 130 & 130 \\
\hline GGBFS: $\mathrm{kg} / \mathrm{m}^{3}$ & 110 & 110 & 110 & 110 \\
\hline Cementitious content: $\mathrm{kg} / \mathrm{m}^{3}$ & 400 & 400 & 400 & 400 \\
\hline Water: litre $/ \mathrm{m}^{3}$ & 208 & 208 & 208 & 208 \\
\hline $\begin{array}{l}\text { Water cementitious ratio } \\
\text { Fine aggregate: } \mathrm{kg} / \mathrm{m}^{3}\end{array}$ & 0.52 & 0.52 & 0.52 & 0.52 \\
\hline Coarse sand & 660 & 660 & 660 & 660 \\
\hline Fine sand & 221 & 221 & 221 & 221 \\
\hline $\begin{array}{l}\text { Coarse aggregate: } \mathrm{kg} / \mathrm{m}^{3} \\
\text { Admixtures: litre } / \mathrm{m}^{3}\end{array}$ & 820 & 820 & 820 & 820 \\
\hline Superplasticiser & 4 & $4 \cdot 86$ & $4 \cdot 73$ & $4 \cdot 5$ \\
\hline VMA & $1 \cdot 3$ & $1 \cdot 3$ & $1 \cdot 3$ & $1 \cdot 3$ \\
\hline $\begin{array}{l}\text { High range water reducing agent } \\
\text { Fibre content: } \mathrm{kg} / \mathrm{m}^{3}\end{array}$ & $1 \cdot 6$ & $1 \cdot 6$ & $1 \cdot 6$ & 1.6 \\
\hline Steel & - & 30 & - & 15 \\
\hline PP & - & - & 5 & 3 \\
\hline
\end{tabular}

GGBFS: ground granulated blast furnace slag; PP: polypropylene.

Table 8. The proportions of the concrete mixtures (based on SSD condition) 
This study performed slump flow, $T_{50 \mathrm{~cm}}$ time, J-ring flow, V-funnel flow time and L-box blocking ratio tests. In order to reduce the effect of loss of workability on the variability of test results, the fresh properties of the mixes were determined within 30 min of mixing. The order of testing is as follows

- slump flow test and measurement of $T_{50 \mathrm{~cm}}$ time

- J-ring flow test, measurement of difference in height of concrete inside and outside the J-ring, and measurement of $T_{50 \mathrm{~cm}}$ time

- V-funnel flow tests at $10 \mathrm{~s} T_{10 \mathrm{~s}}$

- L-box test.

\section{Experimental results}

\section{Properties of fresh concrete}

The results of various fresh properties tested by the slump flow test (slump flow diameter and $T_{50 \mathrm{~cm}}$ ); J-ring test (flow diameter); L-box test (time taken to reach $400 \mathrm{~mm}$ distance $T_{400 \mathrm{~mm}}$, time taken to reach $600 \mathrm{~mm}$ distance $T_{600 \mathrm{~mm}}$, time taken to reach $800 \mathrm{~mm}$ distance $T_{\mathrm{L}}$ and ratio of heights at the two edges of L-box $\left[\mathrm{H}_{2} / \mathrm{H}_{1}\right]$ ); V-funnel test (time taken by concrete to flow through V-funnel after $10 \mathrm{~s} T_{10 \mathrm{~s}}$ ); the amount of entrapped air; and the specific gravity of mixes are given in Table 9 . The slump flow test judges the capability of concrete to deform under its own weight against the friction of the surface with no restraint present. A slump flow value ranging from 500 to $700 \mathrm{~mm}$ for SCC was suggested (EFNARC, 2005). At a slump flow $>700 \mathrm{~mm}$, the concrete might segregate, and at $<500 \mathrm{~mm}$, the concrete might have insufficient flow to pass through highly congested reinforcements. All the mixes in the present study conform to the above range because the slump flow of SCC is in the range of $600-700 \mathrm{~mm}$. The slump flow time for the concrete to reach a diameter of $500 \mathrm{~mm}$ for all mixes was less than $4.5 \mathrm{~s}$. The J-ring diameters were in the range of $560-655 \mathrm{~mm}$. In addition to the slump flow test, a V-funnel test was also performed to assess the flowability and stability of SCC. V-funnel flow time is the elapsed time, in seconds, between the opening of the bottom outlet, depending when it is opened ( $T_{10 \mathrm{~s}}$ and $\left.T_{5 \min }\right)$, and the time when light becomes visible at the bottom when observed from the top. A V-funnel time of less than $6 \mathrm{~s}$ is recommended for SCC. According to EFNARC (2005), a period ranging from 6 to $12 \mathrm{~s}$ is considered adequate for SCC.

The V-funnel flow times in the experiment were in the range of $7-11 \mathrm{~s}$. The test results of this investigation indicated that all mixes met the requirements of allowable flow time. V-funnel flow time test results for the N-SCC mix was about $6 \mathrm{~s}$ and for the D-SCC was $7 \mathrm{~s}$; for other fibre reinforced SCC mixes are blocked.

The maximum size of coarse aggregate was restricted to $10 \mathrm{~mm}$ to avoid a blocking effect in the L-box for N-SCC mix. The gap between rebars in the L-box test was $35 \mathrm{~mm}$. The L-box ratio $\mathrm{H}_{2} / \mathrm{H}_{1}$ for the N-SCC mix was above $0 \cdot 8$, which is according to EFNARC standards and for other mixes is blocked.

\section{Compressive and tensile strength results}

Figure 1 shows the compressive strength experimental results for cube specimens with 100 and $150 \mathrm{~mm}$ dimensions, and for cylinder specimens with $100 \times 200$ and $150 \times 300 \mathrm{~mm}$ dimensions. The tensile strength experimental results for cylinder specimens with dimensions of $100 \times 200$ and $150 \times 300 \mathrm{~mm}$ are shown in Figure 1. In this figure, compressive and tensile strength results for all mixes are shown at the ages of 3, 7, 14, 28 and 56 days.

A general comparison of the compressive strengths of cubes of 100 and $150 \mathrm{~mm}$ shows that the DS-SCC mix had higher compressive strength than other mixes. Also, the N-SCC mix had the lowest compressive strength and the S-SCC mix had higher compressive strength than the D-SCC mixes (see Figures 1(a) and 1(b)). However, the comparisons of the compressive strengths of 150 -mm cubes show that the N-SCC mix strength is $11 \cdot 15 \%$ higher, the D-SCC mix is $9 \cdot 16 \%$ higher, the S-SCC mix is $7 \cdot 56 \%$ higher and the DS-SCC mix is $7 \cdot 83 \%$ higher than the compressive strengths of 100 -mm cubes.

\begin{tabular}{|c|c|c|c|c|c|}
\hline Workability characteristics & ACI 237R-07 and EFNARC & $\mathrm{N}-\mathrm{SCC}$ & D-SCC & S-SCC & DS-SCC \\
\hline Average spreading diameter: $\mathrm{mm}$ & $650-800$ & 680 & 670 & 700 & 650 \\
\hline Flow time $T_{50 \mathrm{~cm}}: \mathrm{s}$ & $2 \cdot 5-5$ & $2 \cdot 7$ & $3 \cdot 8$ & $2 \cdot 5$ & $3 \cdot 2$ \\
\hline Average J-ring diameter: mm & $650-800$ & 655 & 580 & 570 & 560 \\
\hline Flow time $T_{50 \mathrm{~cm}}$ J-ring: $\mathrm{s}$ & $2 \cdot 5-5$ & $3 \cdot 2$ & 5 & 6 & 5 \\
\hline L-box test & $0 \cdot 8-1 \cdot 0$ & $0 \cdot 87$ & Blocked & Blocked & Blocked \\
\hline Flow time V-funnel: s & $6-12$ & 6 & 7 & Blocked & Blocked \\
\hline Entrapped air: \% & - & $1 \cdot 3$ & $1 \cdot 2$ & $1 \cdot 2$ & $1 \cdot 0$ \\
\hline Specific gravity: $\mathrm{kg} / \mathrm{m}^{3}$ & - & 2340 & 2274 & 2330 & 2385 \\
\hline
\end{tabular}




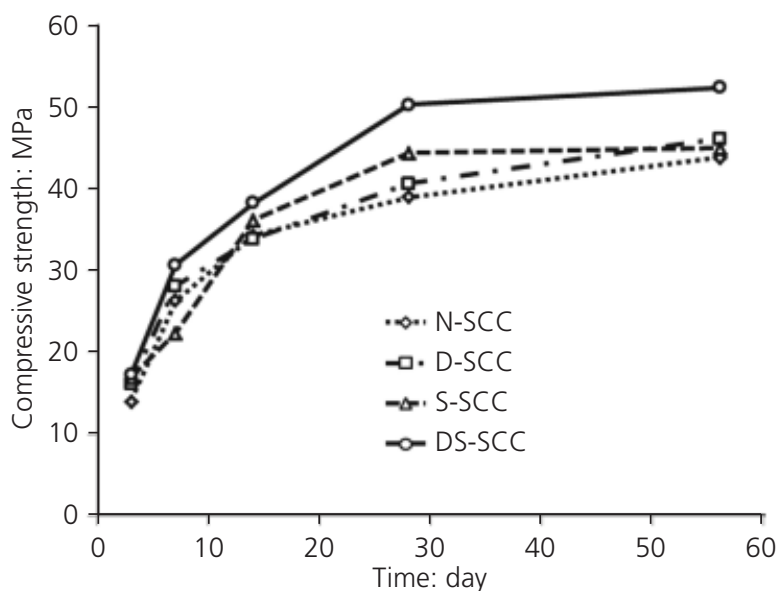

(a)

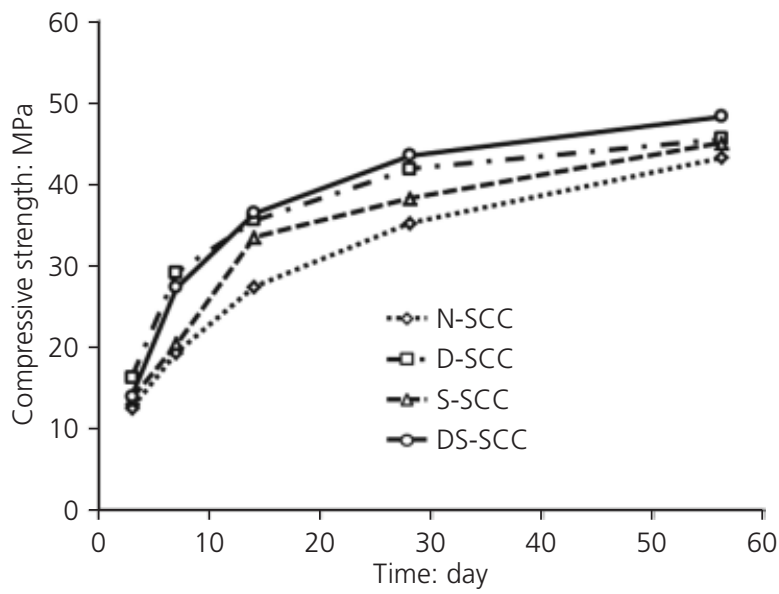

(c)

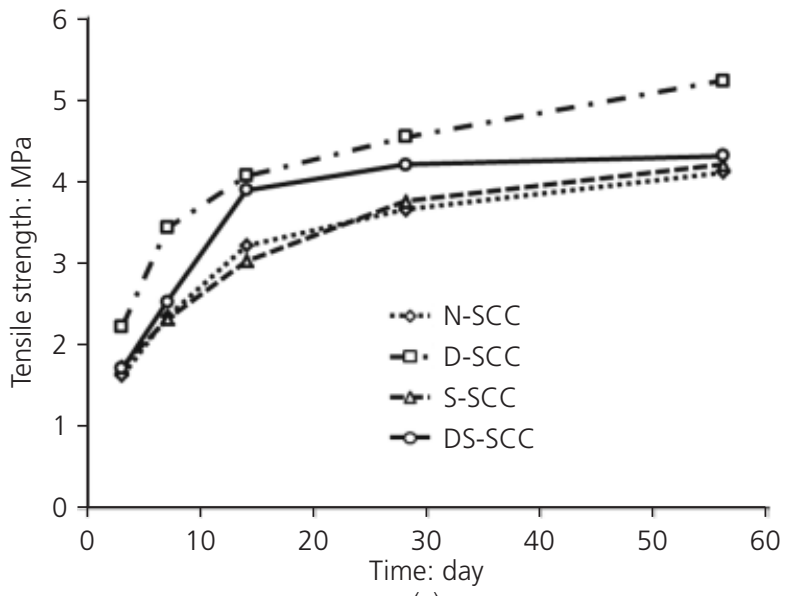

(e)

Figure 1. Compressive and tensile strengths (a) cube $100 \mathrm{~mm}$ (b) cube $150 \mathrm{~mm}$, (c) cylinder $100 \times 200 \mathrm{~mm}$, (d) cylinder $150 \times 300 \mathrm{~mm}$, (e) cylinder $100 \times 200 \mathrm{~mm}$ and (f) cylinder $150 \times 300 \mathrm{~mm}$
Effects of specimen size and shape on

compressive and tensile strengths of

self-compacting concrete with or without

fibres

Aslani

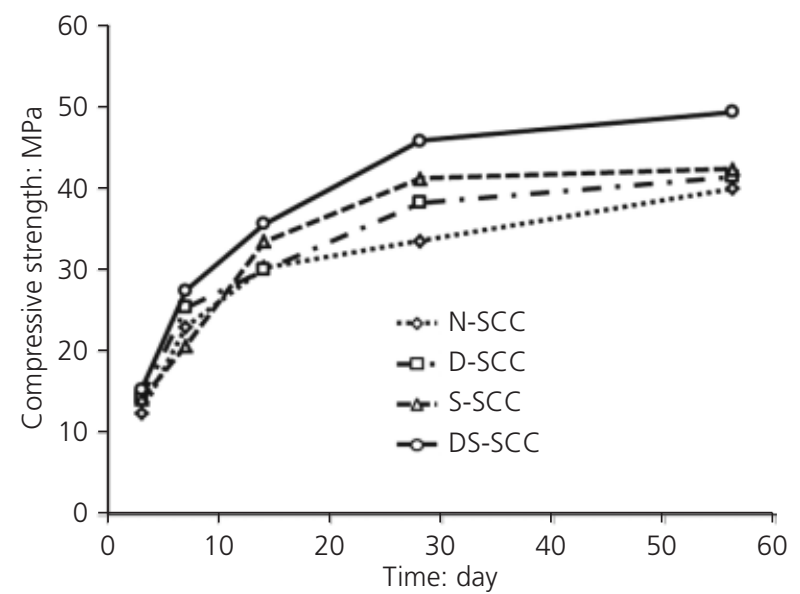

(b)

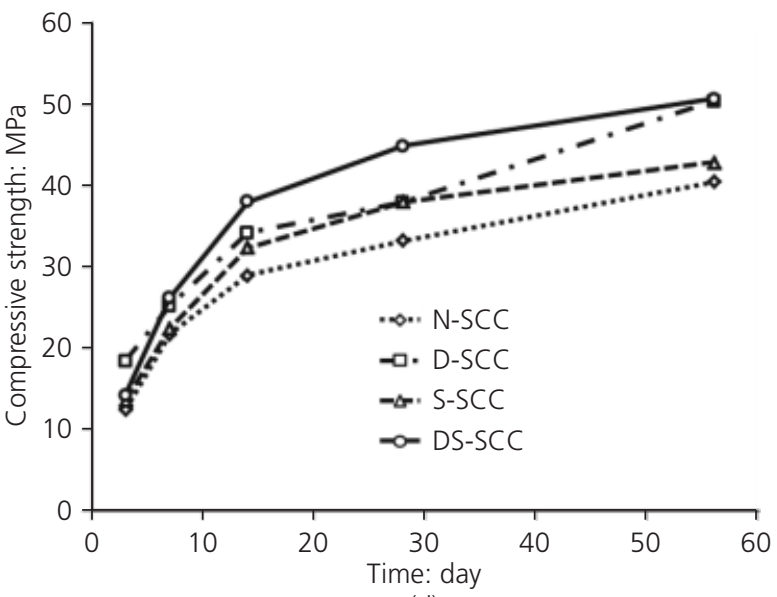

(d)

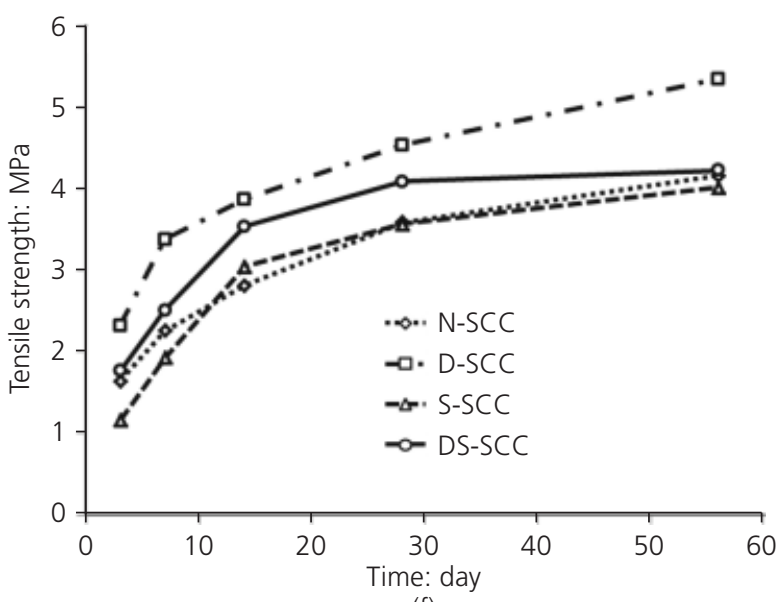

(f) 
Figures 1(c) and 1(d) show that DS-SCC has higher compressive strength than other mixes, and that S-SCC mix has the lowest compressive strength for $100 \times 200$ and $150 \times 300$-mm cylinders. The comparisons of the compressive strengths of $150 \times 300 \mathrm{~mm}$ cylinders show that the N-SCC mix strength is $0.5 \%$ higher, the D-SCC mix is $1.22 \%$ higher, the S-SCC mix is $0.93 \%$ higher and the DS-SCC mix is $2.65 \%$ lower than the compressive strengths of $100 \times 200 \mathrm{~mm}$ cylinders.

Figures 1(e) and 1(f) show that D-SCC has a higher tensile strength, and N-SCC and S-SCC have lower tensile strengths for $100 \times 200$ and $150 \times 300 \mathrm{~mm}$ cylinders. The comparisons of the tensile strengths of $150 \times 300 \mathrm{~mm}$ cylinders show that the $\mathrm{N}$ SCC mix strength is $3 \cdot 2 \%$ higher, the D-SCC mix is $0 \cdot 16 \%$ higher the S-SCC mix is $8.8 \%$ higher and the DS-SCC mix is $3 \cdot 1 \%$ lower than the tensile strengths of $100 \times 200 \mathrm{~mm}$ cylinders.

\section{Theoretical analysis}

Theoretical analysis of the size effect

Bazant (1984) and Kim and Eo (1990) proposed the modified size effect law (MSEL; Equation 1) by adding the size independent strength $\sigma_{0}\left(=\alpha f_{\mathrm{ct}}\right)$ to the size effect law to predict the strength of concrete structures with or without initial cracks, and with similar or dissimilar cracks (Yi et al., 2006). This concept was also proposed by Bazant $(1987,1993)$ and Bazant and Xiang (1997), with a different solution procedure

$$
\sigma_{\mathrm{N}}(d)=\frac{B f_{\mathrm{ct}}}{\sqrt{1+d / \lambda_{\mathrm{o}} d_{\mathrm{a}}}}+\alpha f_{\mathrm{ct}}
$$

where $\sigma_{\mathrm{N}}(d)$ is the nominal strength; $f_{\mathrm{ct}}$ is the direct tensile strength; $d$ is the characteristic dimension; $d_{\mathrm{a}}$ is the maximum aggregate size; and $B, \lambda_{\mathrm{o}}$ and $\alpha$ are the empirical constants.

Although the failure mechanism and effect of size on tensile failure have been studied extensively, the behaviour of compressive failure has not been sufficiently studied in comparison. Concrete is a construction material normally used to withstand compressive force. Accordingly, more studies in this field are necessary. As it is logical to extend the tensile size effect research to compressive failure research, the direct tensile strength $f_{\mathrm{ct}}$ used in the MSEL must be substituted with the compressive strength of standard cylinder $f_{\mathrm{c}}^{\prime}$ in the new equation for the prediction of the effect of size on compression. This substitution can be done because, even though the tensile failure mechanism is different from the compressive failure mechanism, the ultimate failure of both is attributable to the propagation of macro-crack, indicating a localised tension or mode I failure. Therefore, it is safe to assume that the tensile fracture-based concept can be applied to compressive failure as well. The validity of the MSEL was demonstrated by regression analyses on available test data for tensile strength, shear strength and uniaxial compressive strength.
As an application of MSEL, some studies have been performed on unnotched and notched cylindrical specimens subjected to uniaxial compressive force; on axially loaded, double-cantilever beams; and on $\mathrm{C}$-shaped specimens subjected to flexural compression force. In Equation 1, the width of crack band $l_{\mathrm{o}}$ is empirically found to be related to the maximum aggregate size $d_{\mathrm{a}}$ (in this study, $d_{\mathrm{a}}=10 \mathrm{~mm}$ ), for example $l_{\mathrm{o}}=\lambda_{\mathrm{o}} d_{\mathrm{a}}$ in which $\lambda_{\mathrm{o}}$ is an approximate constant with values between 2.0 and 3.0 (Bazant, 1984; Kim et al., 1999, 2000, 2001). In the regression analysis, this constant is selected as $2 \cdot 0$, where $l_{\mathrm{o}}=2 \cdot 0$ and $d_{\mathrm{a}}=20 \cdot 0 \mathrm{~mm}$. In a previous study (Kim et al., 1999), Equation 2 was proposed to obtain the compressive strength of cylindrical concrete specimens with various diameters and height/diameter ratios. For this purpose, the effects of the maximum aggregate size on the fracture process zone were considered and the concept of characteristic length was newly introduced. The method to determine the characteristic length is derived and explained by Kim and Eo (1990).

$$
\text { 2. } \sigma_{\mathrm{N}}(h d)=\frac{0 \cdot 4 f_{\mathrm{c}}^{\prime}}{\sqrt{1+(h-d) / 5}}+0 \cdot 8 f_{\mathrm{c}}^{\prime}
$$

where the height of cylinder specimen $h$ and the diameter of cylinder specimen $d$ are in $\mathrm{cm}$. Equation 2 was compared with the ASTM standard (ASTM, 2000), and it was noted that the prediction values of Equation 2 are less than those of the ASTM standard, but the difference is minimal.

\section{Size effect for cubes}

Figure 2 shows the value $f_{\mathrm{cmu}}^{\prime}(d) / f_{\mathrm{c}}^{\prime}\left(f_{\mathrm{cmu}}^{\prime}(d)\right.$ is the compressive strength of cube and $f_{\mathrm{c}}^{\prime}$ is the N-SCC mix compressive strength) as a function of the specimen size $d$ and the strong size effect for compressive strengths of cubes. Regression analyses were conducted to measure the compressive strength of the cubes, Equations 3-6 were obtained, and the results were graphed and are shown in Figure 2.

For N-SCC

3. $f_{\mathrm{cmu}}^{\prime}(d)=\frac{1.3 f_{\mathrm{c}}^{\prime}}{\sqrt{1+d / l_{\mathrm{o}}}}+0.62 f_{\mathrm{c}}^{\prime}$

For D-SCC

4.

$$
f_{\mathrm{cmu}}^{\prime}(d)=\frac{1 \cdot 3 f_{\mathrm{cfD}}^{\prime}}{\sqrt{1+d / l_{\mathrm{o}}}}+0.62 f_{\mathrm{cfD}}^{\prime}
$$




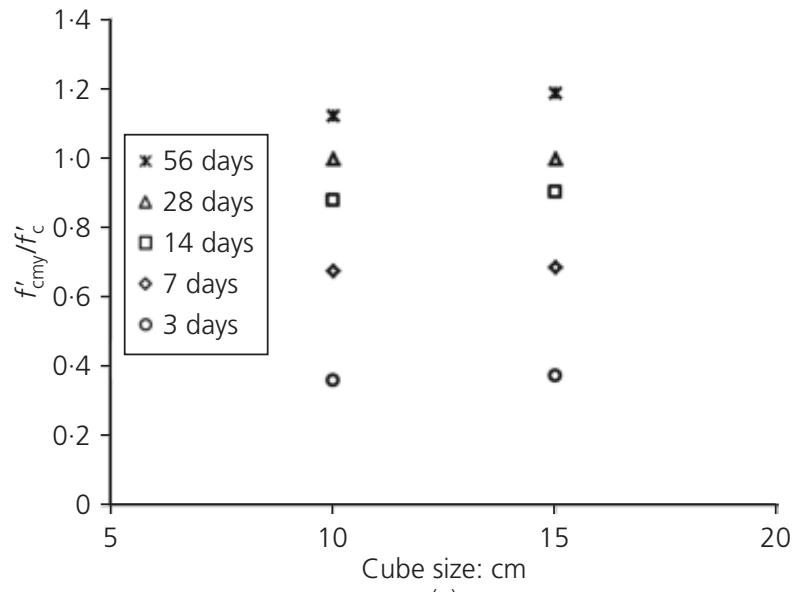

(a)

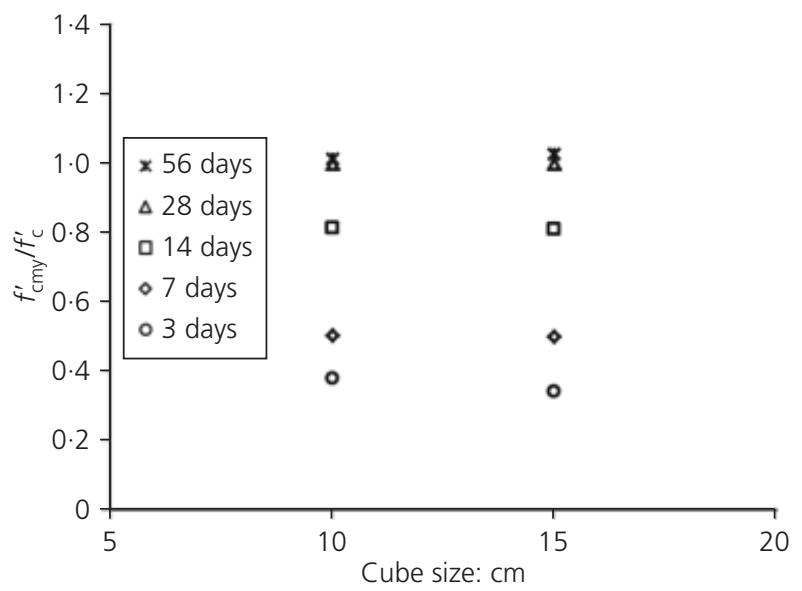

(c)

Figure 2. Compressive strength size effect for cubes (a) N-SCC,

(b) D-SCC, (c) S-SCC and (d) DS-SCC

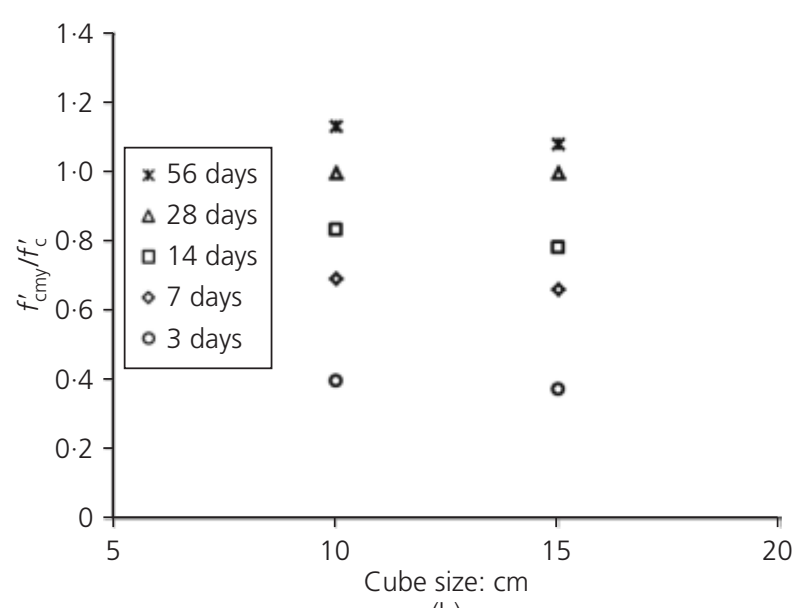

(b)

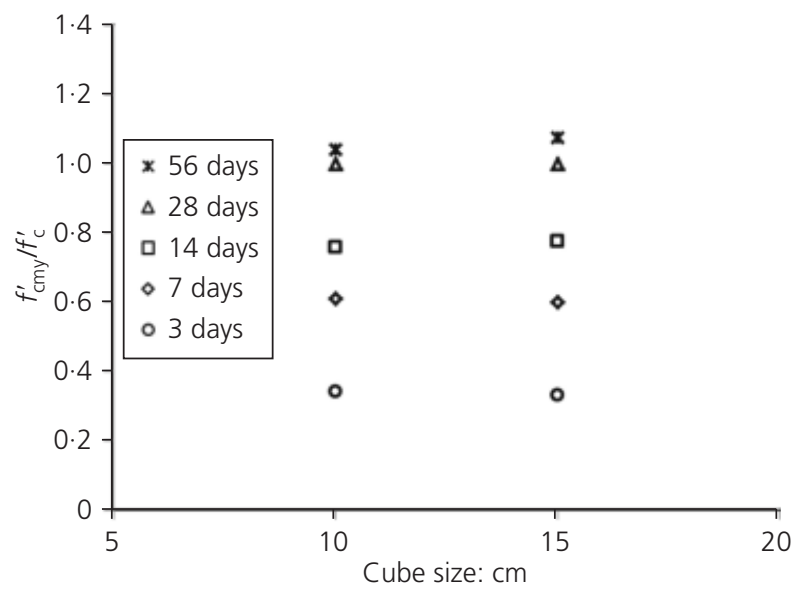

(d)
For S-SCC

5. $f_{\mathrm{cmu}}^{\prime}(d)=\frac{1.3 f_{\mathrm{cfS}}^{\prime}}{\sqrt{1+d / l_{\mathrm{o}}}}+0.62 f_{\mathrm{cfS}}^{\prime}$

For DS-SCC

6.

$$
f_{\mathrm{cmu}}^{\prime}(d)=\frac{1.3 f_{\mathrm{cfDS}}^{\prime}}{\sqrt{1+d / l_{\mathrm{o}}}}+0.62 f_{\mathrm{cfDS}}^{\prime}
$$

where $f_{\mathrm{cfD}}^{\prime}$ is the D-SCC mix compressive strength, $f_{\mathrm{cfS}}^{\prime}$ is the S-SCC mix compressive strength and $f_{\mathrm{cDS}}^{\prime}$ is the DS-SCC mix compressive strength in $\mathrm{MPa}$; the size of the cube $d$ is in $\mathrm{cm}$, $l_{\mathrm{o}}=2 \cdot 0 d_{\mathrm{a}}$ and $d_{\mathrm{a}}$ is the maximum aggregate size. The compressive strengths for the D-SCC, S-SCC and DS-SCC mixes were obtained based on the regression analyses as shown in Equations 7-9.
For D-SCC

7. $f_{c \mathrm{fD}}^{\prime}=f_{\mathrm{c}}^{\prime}+15 \cdot 2$ (R.I.)

For S-SCC

8. $f_{\mathrm{cfS}}^{\prime}=f_{\mathrm{c}}^{\prime}-3$ (R.I.)

For DS-SCC

9. $f_{\mathrm{cfDS}}^{\prime}=f_{\mathrm{c}}^{\prime}+12 \cdot 85$ (R.I.)

where the R.I. is the fibre reinforcing index $\left(=V_{\mathrm{f}} \times l_{\mathrm{f}} / d_{\mathrm{f}}\right)$, fibre volume fractions $\left(V_{\mathrm{f}}\right)$ and aspect ratio $\left(l_{\mathrm{f}} / d_{\mathrm{f}}\right)$. 


\section{Size effect for compressive strength cylinder}

Equations 10-13 were obtained from least squares method regression analyses for cylinders. Figure 3 shows the value $f_{\text {cmy }}^{\prime}(d) / f_{\mathrm{c}}^{\prime}\left(f_{\mathrm{cmy}}^{\prime}(d)\right.$ is the compressive strength with size of general cylinder) as a function of the diameter $d$. In this study, it is concluded that the strength ratio approaches a limit with an increasing diameter $d$.

For N-SCC

$$
10 .
$$

$$
f_{\mathrm{cmy}}^{\prime}(d)=\frac{0.55 f_{\mathrm{c}}^{\prime}}{\sqrt{1+d / l_{\mathrm{o}}}}+0.81 f_{\mathrm{c}}^{\prime}
$$

\section{For D-SCC}

11.

$$
f_{\text {cmy }}^{\prime}(d)=\frac{0 \cdot 55 f_{\mathrm{cfD}}^{\prime}}{\sqrt{1+d / l_{\mathrm{o}}}}+0 \cdot 81 f_{\mathrm{cfD}}^{\prime}
$$

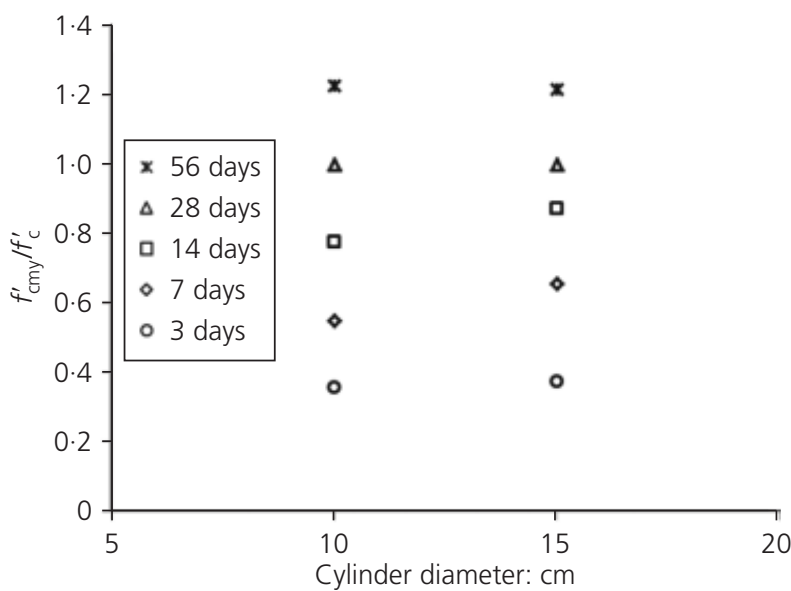

(a)

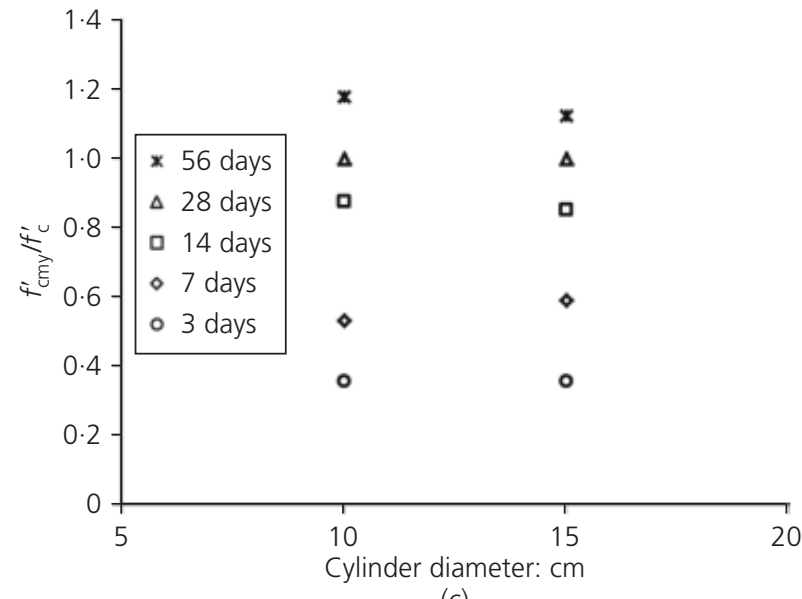

(c)

Figure 3. Compressive strength size effect for cylinders

(a) N-SCC, (b) D-SCC, (c) S-SCC and (d) DS-SCC
For S-SCC

12. $f_{\text {cmy }}^{\prime}(d)=\frac{0.55 f_{\mathrm{cfS}}^{\prime}}{\sqrt{1+d / l_{\mathrm{o}}}}+0.81 f_{\mathrm{cfS}}^{\prime}$

For DS-SCC

13.

$$
f_{\text {cmy }}^{\prime}(d)=\frac{0.55 f_{\text {cfDS }}^{\prime}}{\sqrt{1+d / l_{\mathrm{o}}}}+0 \cdot 81 f_{\mathrm{cfDS}}^{\prime}
$$

where the N-SCC mix compressive strength $f_{\mathrm{c}}^{\prime}$, the D-SCC mix compressive strength $f_{\mathrm{cfD}}^{\prime}$ (Equation 7), the S-SCC mix compressive strength $f_{\mathrm{cfS}}^{\prime}$ (Equation 8 ) and the DS-SCC mix compressive strength $f_{\text {cfDS }}$ (Equation 9) are in MPa, and size of the cylinder $d$ is in $\mathrm{cm}$, where $l_{\mathrm{o}}=2 \cdot 0 d_{\mathrm{a}}$, and $d_{\mathrm{a}}$ is the maximum aggregate size. The term 'general' represents the cylinders with arbitrary chosen dimensions.

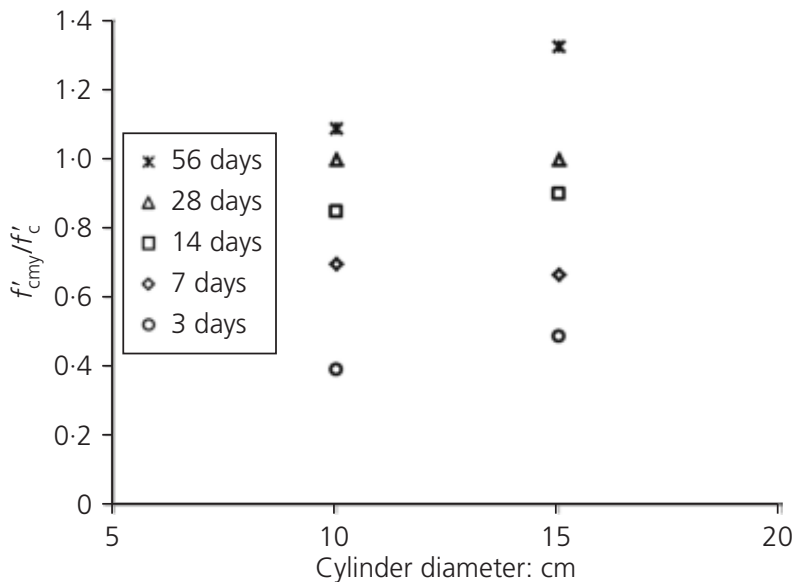

(b)

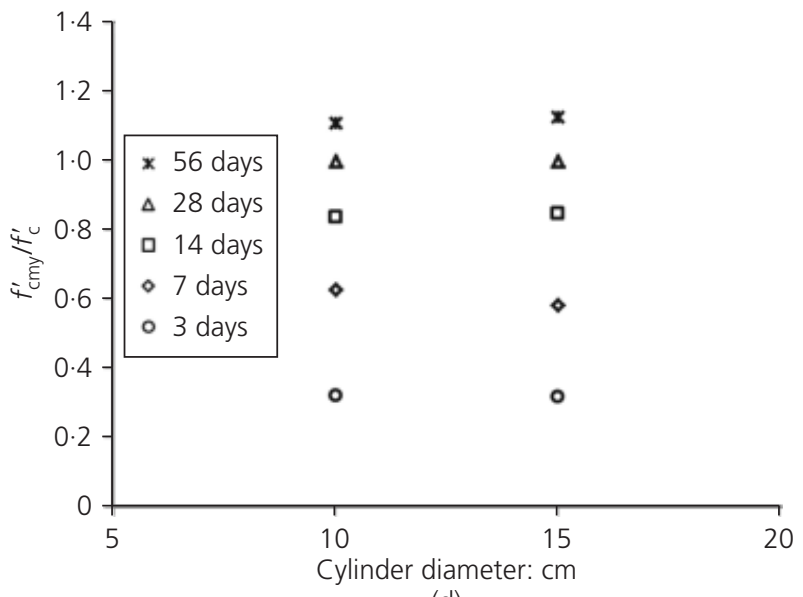

(d) 


\section{Size effect for tensile strength cylinder}

Figure 4 shows the value $f_{\text {ctmy }}(d) / f_{\text {ct }}\left(f_{\text {ctmy }}(d)\right.$ is the tensile strength of cylinder and $f_{\text {ct }}$ is the N-SCC mix tensile strength) as a function of the specimen size $d$ and the strong size effect for tensile strengths of cubes. Regression analyses were conducted to measure the tensile strengths of the cubes, Equations 14-17 were obtained, and the results were graphed and are shown in Figure 4.

For N-SCC

14. $f_{\text {ctmy }}(d)=\frac{0 \cdot 8 f_{\text {ct }}}{\sqrt{1+d / l_{\mathrm{o}}}}+0.72 f_{\mathrm{ct}}$

\section{For D-SCC}

15.

$$
f_{\text {ctmy }}(d)=\frac{0.8 f_{\mathrm{fctD}}}{\sqrt{1+d / l_{\mathrm{o}}}}+0.72 f_{\mathrm{fctD}}
$$

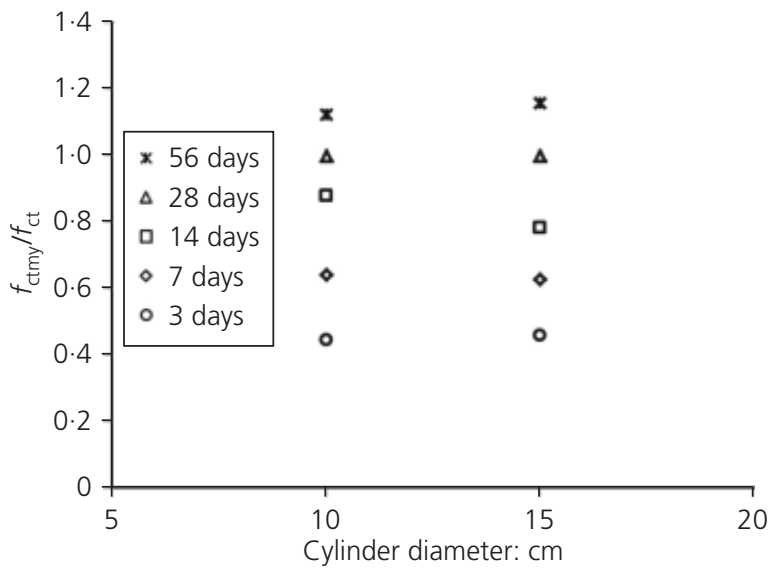

(a)

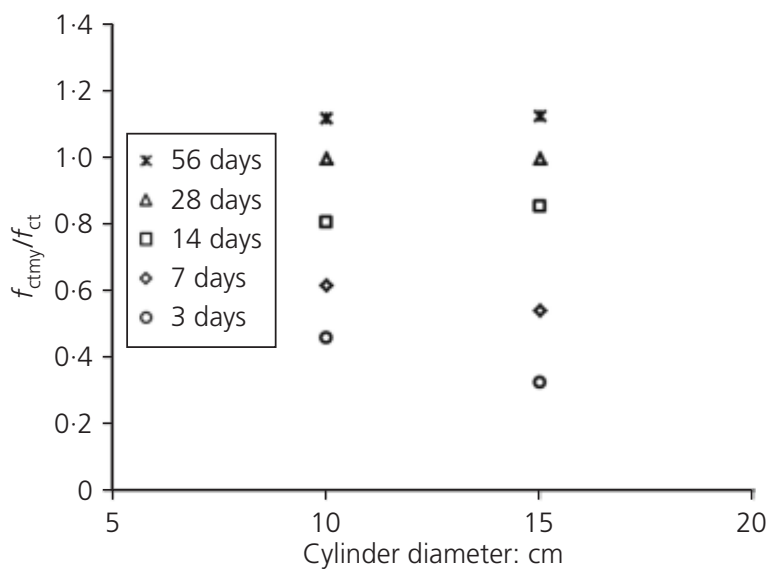

(c)

Figure 4. Tensile strength size effect for cylinders (a) N-SCC,

(b) D-SCC, (c) S-SCC and (d) DS-SCC
For S-SCC

16.

$$
f_{\text {ctmy }}(d)=\frac{0 \cdot 8 f_{\text {fctS }}}{\sqrt{1+d / l_{\mathrm{o}}}}+0.72 f_{\mathrm{fctS}}
$$

For DS-SCC

17. $f_{\text {ctmy }}(d)=\frac{0 \cdot 8 f_{\text {fctDS }}}{\sqrt{1+d / l_{\mathrm{o}}}}+0.72 f_{\mathrm{fctDS}}$

where the D-SCC mix tensile strength $f_{\text {ftD }}$, the S-SCC mix tensile strength $f_{\text {fts }}$ and the DS-SCC mix tensile strength $f_{\text {ftDS }}$ are in $\mathrm{MPa}$, and the size of the cylinder $d$ is in $\mathrm{cm}$, where $l_{\mathrm{o}}=2 \cdot 0 d_{\mathrm{a}}$ and $d_{\mathrm{a}}$ is the maximum aggregate size. The tensile strength for the D-SCC, S-SCC and DS-SCC mixes were obtained based on the regression analyses as shown in Equations $18-20$.

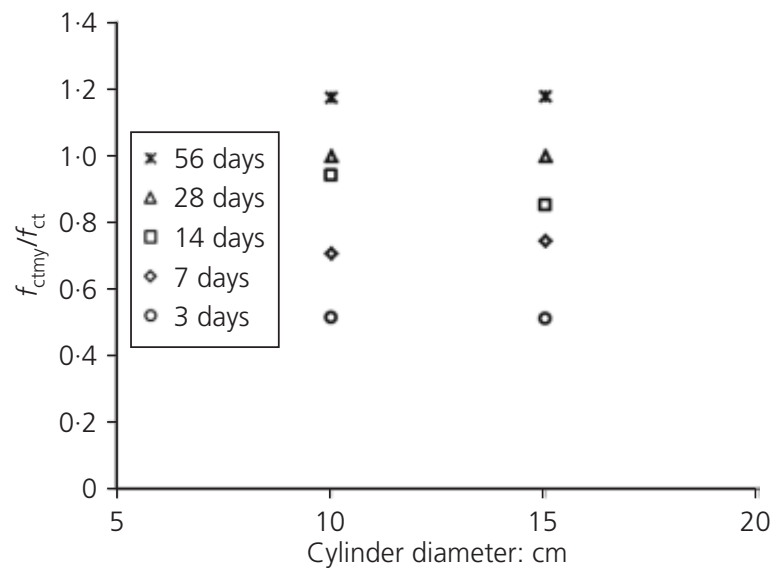

(b)

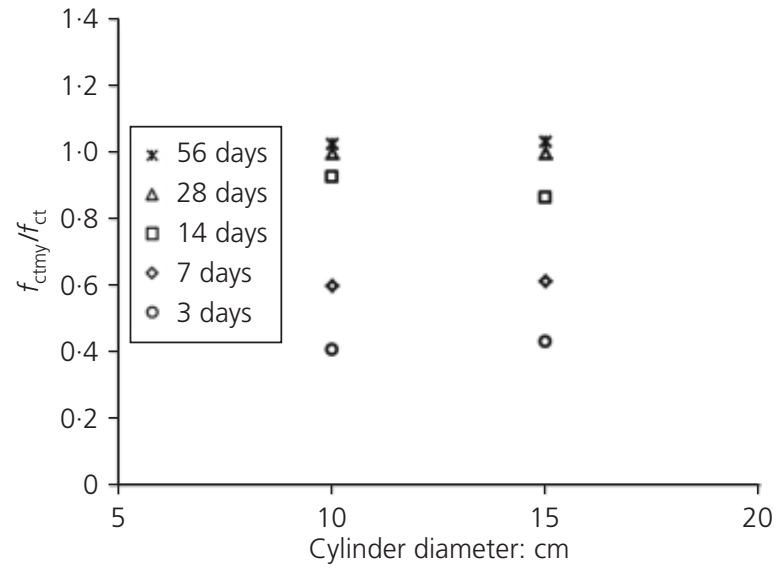

(d) 


\section{For D-SCC}

18. $f_{\mathrm{fctD}}=f_{\mathrm{ct}}+5 \cdot 1$ (R.I.)

For S-SCC

19. $f_{\mathrm{fctS}}=f_{\mathrm{ct}}-3$ (R.I.)

\section{For DS-SCC}

20. $f_{\mathrm{fctDS}}=f_{\mathrm{ct}}+4 \cdot 3$ (R.I.)

where the R.I. is the fibre reinforcing index $\left(=V_{\mathrm{f}} \times l_{\mathrm{f}} / d_{\mathrm{f}}\right)$, fibre volume fractions $\left(V_{\mathrm{f}}\right)$ and aspect ratio $\left(l_{\mathrm{f}} / d_{\mathrm{f}}\right)$.

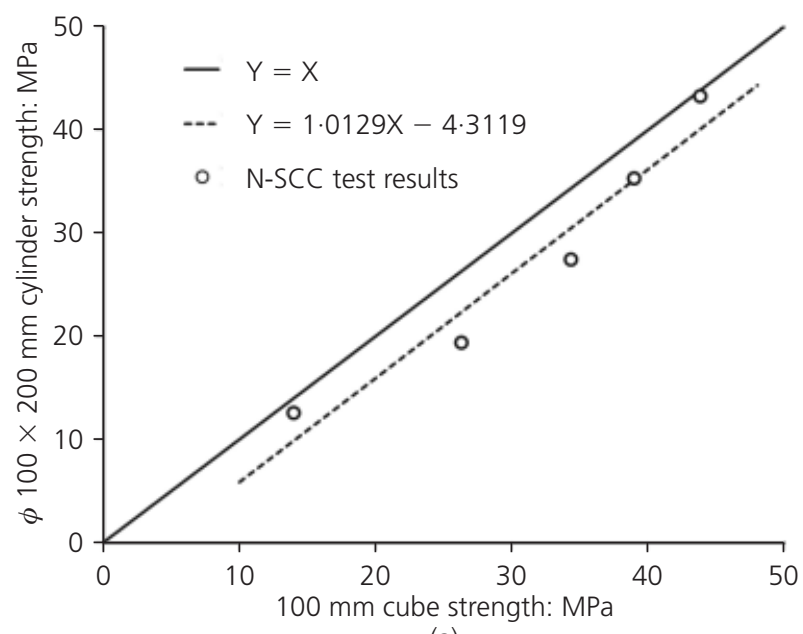

(a)

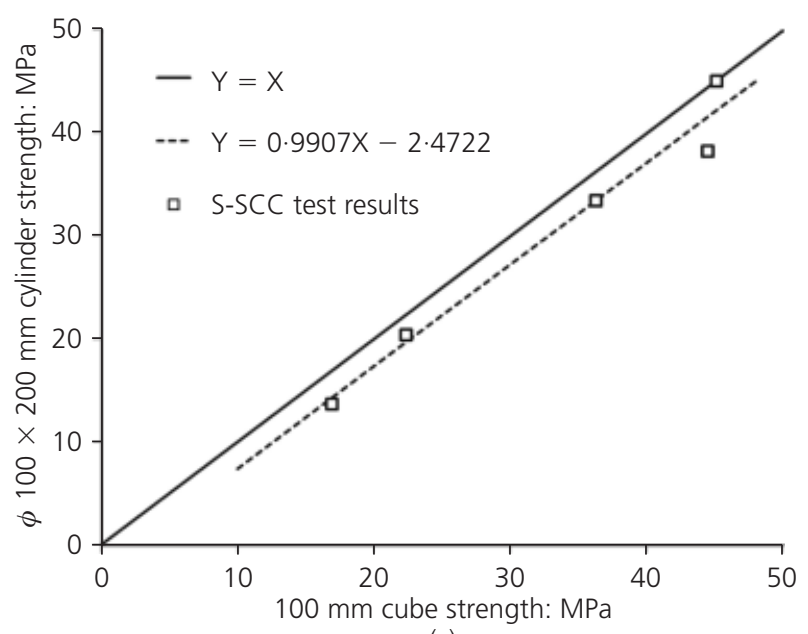

(c)

Figure 5. Relationship between compressive strengths of the $100 \times 200 \mathrm{~mm}$ cylinder and the $100 \mathrm{~mm}$ cube. (a) N-SCC,

(b) D-SCC, (c) S-SCC and (d) DS-SCC

\section{Relationship between specimen shapes}

Figures 5-8 show plot the cylinders' against the cubes' compressive strengths for the represented specimen sizes. In these figures, solid lines and dashed lines indicate the best-fit lines obtained from linear regression analyses and the lines of equality $\mathrm{Y}=\mathrm{X}$ respectively. In addition, the equations shown in Figures 5-8 are achieved from linear regression analyses with test data points. The $100 \times 200 \mathrm{~mm}$ cylinder strength, when plotted against the corresponding $100 \mathrm{~mm}$ cube strength, is shown in Figure 5. Figures 5(a), 5(c) and 5(d) show that the $100 \mathrm{~mm}$ cube strength is higher for N-SCC, S-SCC and DS-SCC. Figure 5(b) shows that the $100 \mathrm{~mm}$ cube strength is a bit lower than the $100 \times 200 \mathrm{~mm}$ cylinder strength for D-SCC.

The $100 \times 200 \mathrm{~mm}$ cylinder strength, when plotted against the corresponding $150 \mathrm{~mm}$ cube strength, is shown in Figure 6. Figure 6(a) shows that cube strength is higher for lower grades of

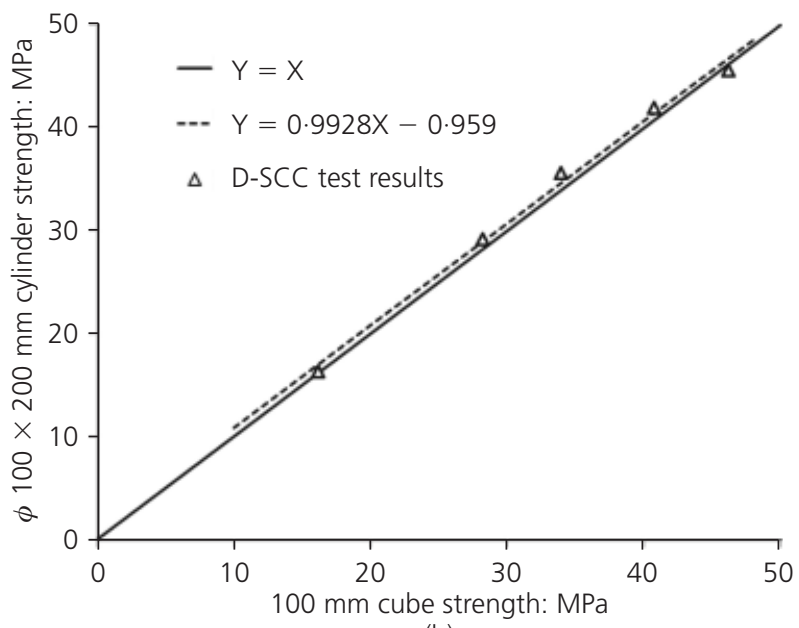

(b)

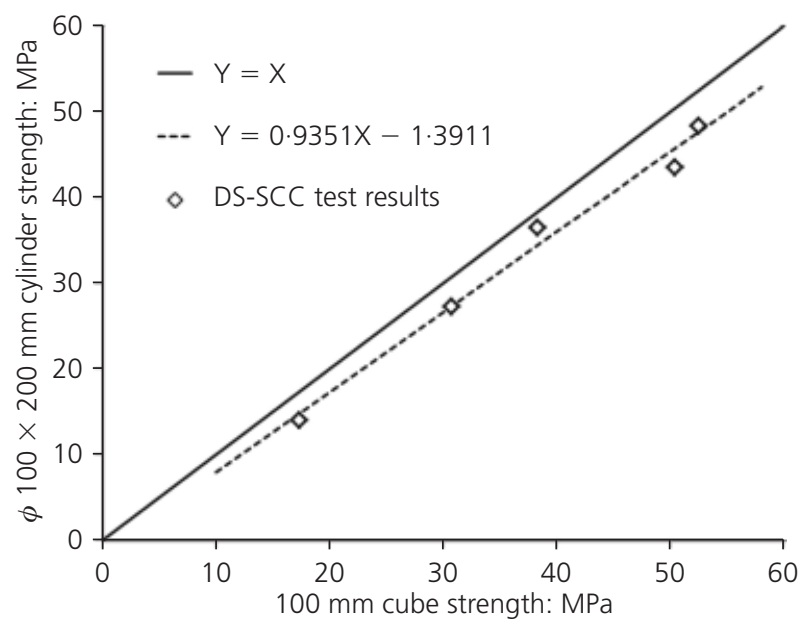

(d) 


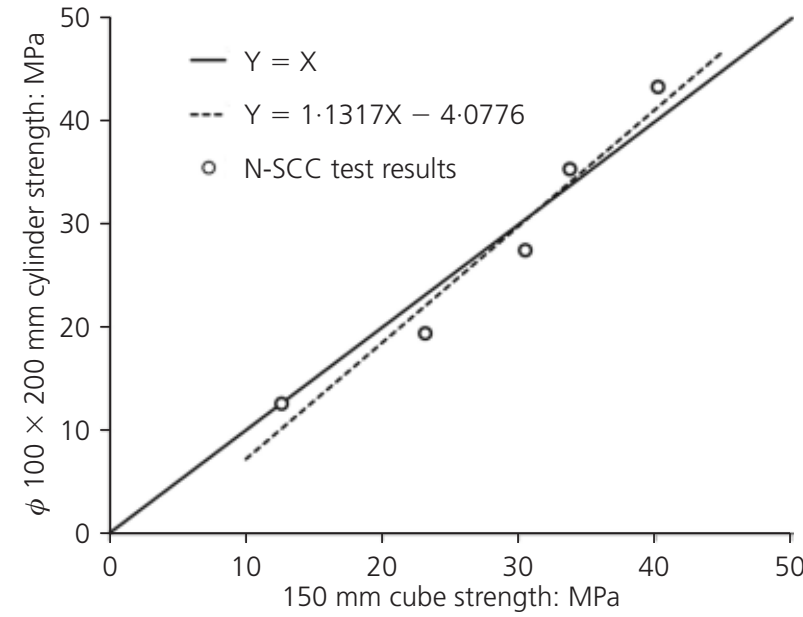

(a)

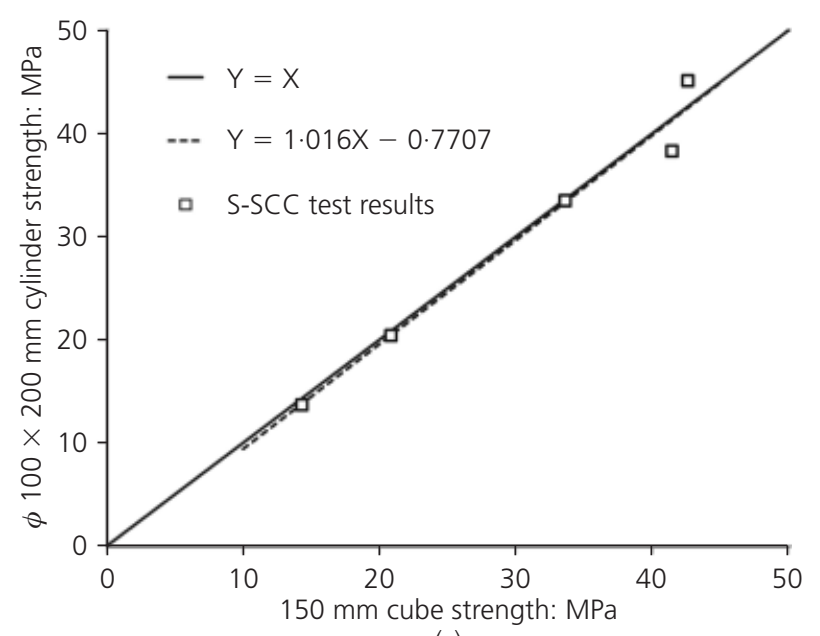

(c)

Figure 6. Relationship between compressive strengths of the $100 \times 200 \mathrm{~mm}$ cylinder and the $150 \mathrm{~mm}$ cube. (a) N-SCC,

(b) D-SCC, (c) S-SCC, and (d) DS-SCC

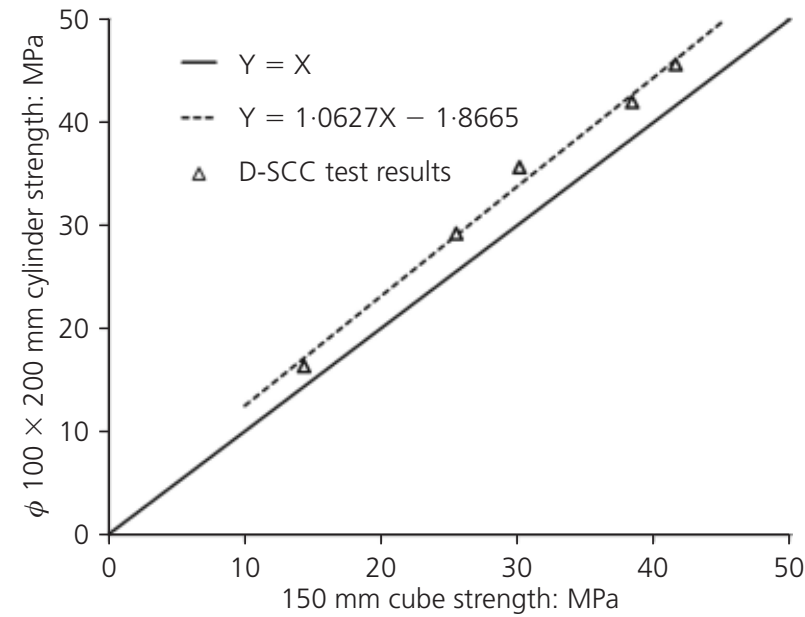

(b)

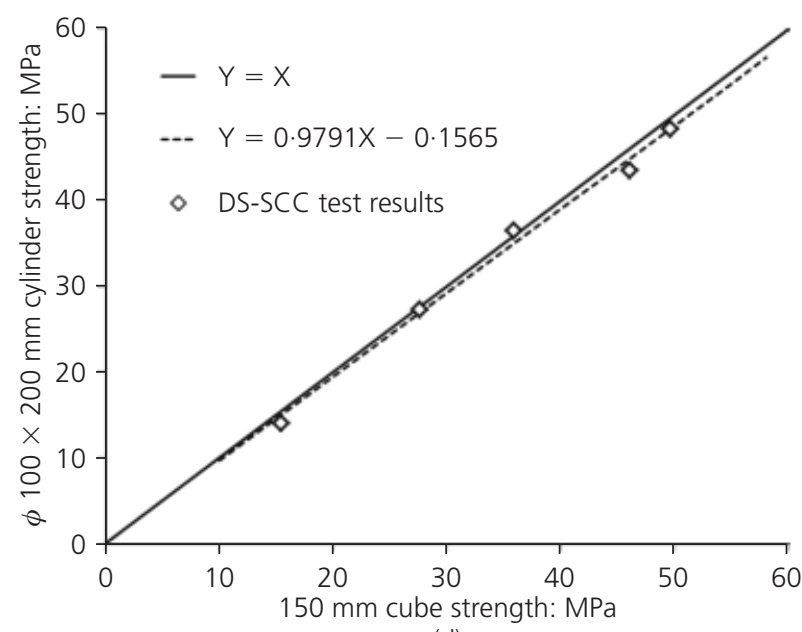

(d)
N-SCC. At approximately $30 \mathrm{MPa}$, however, the strengths become identical. Beyond that point, standard cylinders indicate a slightly higher strength than corresponding cubes do. Figures 6(c) and 6(d) show that the $150 \mathrm{~mm}$ cube strength is nearly identical for the S-SCC and DS-SCC mixes. Figure 5(b) shows that the $150 \mathrm{~mm}$ cube strength is lower than the $100 \times 200 \mathrm{~mm}$ cylinder strength for D-SCC. The $150 \times 300 \mathrm{~mm}$ cylinder strength, when plotted against the corresponding $100 \mathrm{~mm}$ cube strength, is shown in Figure 7. Figures 7(a), 7(c) and 7(d) show that the $100 \mathrm{~mm}$ cube strength is higher for the N-SCC, S-SCC and DS-SCC mixes. Figure $7(\mathrm{~b})$ shows that the $100 \mathrm{~mm}$ cube strength is identical to the $100 \times 200 \mathrm{~mm}$ cylinder strength for D-SCC.

The $150 \times 300 \mathrm{~mm}$ cylinder strength, when plotted against the corresponding $150 \mathrm{~mm}$ cube strength, is shown in Figure 8 . Figures 8 (a) and $8(\mathrm{~d})$ show that the $150 \mathrm{~mm}$ cube strength is nearly identical for N-SCC and DS-SCC mixes. Figure 8(b) shows that the $150 \mathrm{~mm}$ cube strength is lower than the $150 \times 300 \mathrm{~mm}$ cylinder strength for D-SCC. Figure $8(\mathrm{c})$ shows that cube strength is higher for lower grades of S-SCC. At approximately $250 \mathrm{MPa}$, however, the strengths became identical. Beyond that point, standard cylinders indicated a slightly higher strength than the corresponding cubes did.

\section{Conclusions}

Conclusions can be drawn from this experimental and theoretical study, as outlined below.

- Size effect based on the specimen size and shape difference is present for SCC and FRSCC mixes.

- The effect of size on cubes is greater than that on cylinders for all the examined SCC mixes. 


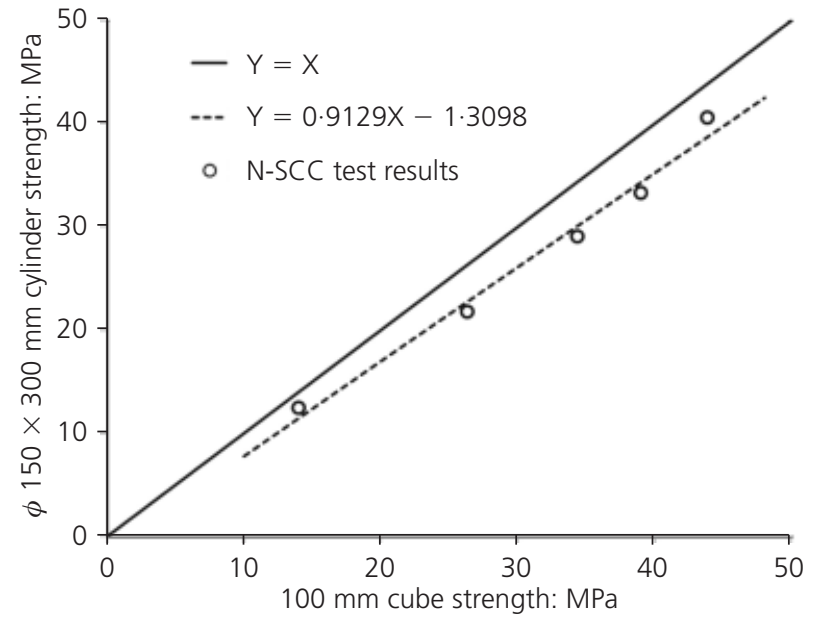

(a)

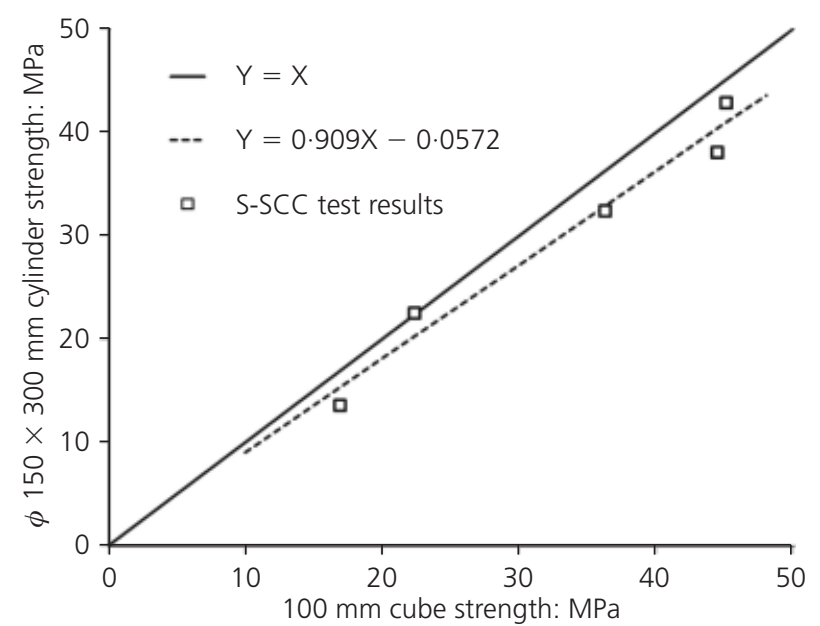

(c)

Figure 7. Relationship between compressive strengths of the $150 \times 300 \mathrm{~mm}$ cylinder and the $100 \mathrm{~mm}$ cube. (a) N-SCC, (b) D-SCC, (c) S-SCC and (d) DS-SCC

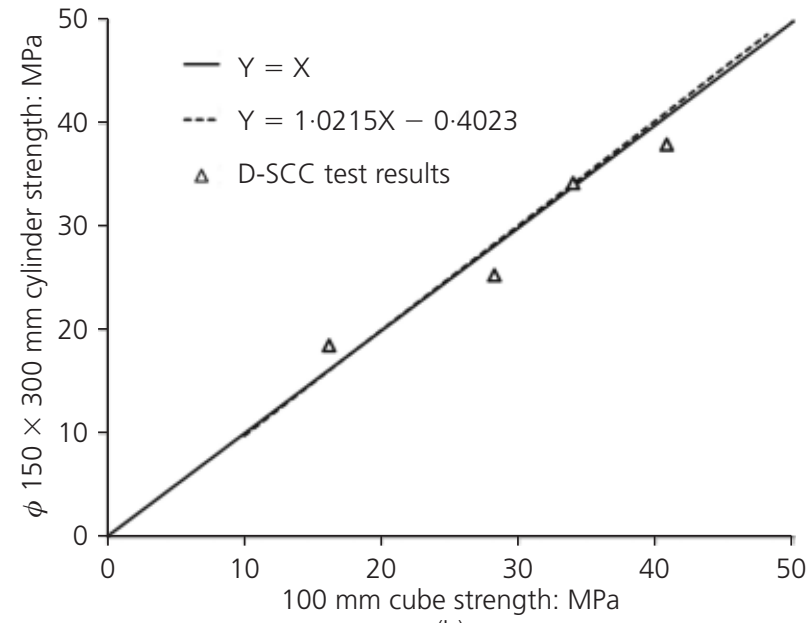

(b)

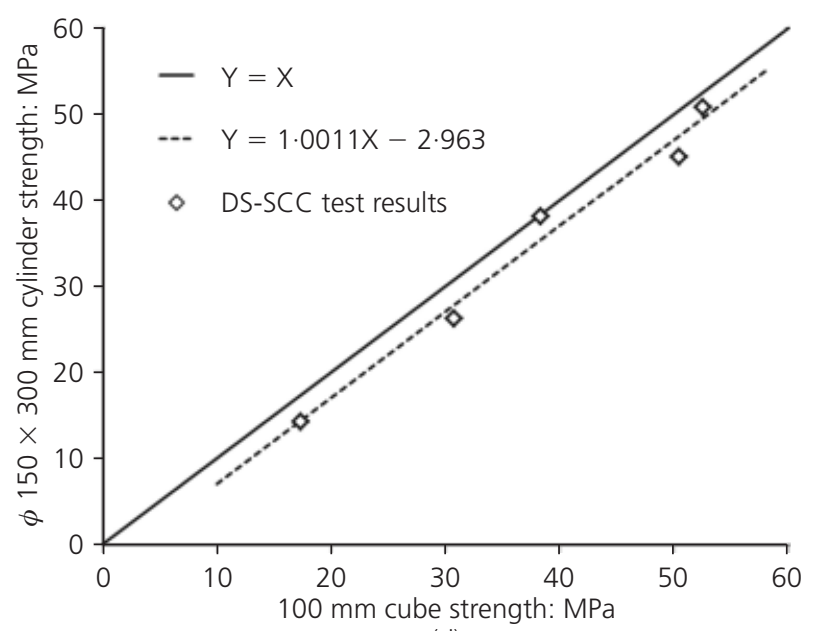

(d)
- The DS-SCC mix has a higher compressive strength than the other mixes in all specimens. Additionally, the D-SCC mix has a higher tensile strength than the other mixes for $100 \times 200 \mathrm{~mm}(3.93 \times 7.87 \mathrm{in})$ and $150 \times 300 \mathrm{~mm}$ $(5.90 \times 11.81$ in $)$ cylinders.

- To obtain the concrete compressive and tensile strengths, the relationships of the size effect for cubes and for cylinders were suggested based on fracture mechanics. Furthermore, these relationships are applicable to N-SCC, D-SCC, S-SCC and DS-SCC.

- The proposed relationship of the size effect for cubes and for compressive and tensile cylinders begins with the same principle. However, in reinforced SCC mixtures, the compressive and tensile strength equations are different; this phenomenon is related to the compressive and tensile strength of N-SCC and the fibre reinforcing index.

- The presented test results show the existence of a shape effect. Shape effect analyses show that the cube's strength is lower or nearly equal to the cylinder's strength for D-SCC mix for all dimensions. Furthermore, these analyses illustrated that the cube's strength is higher or nearly identical to the cylinder's strength for N-SCC, S-SCC and DS-SCC for all dimensions.

- The proposed relationships are useable for FRSCC and normal SCC. However, the main parameter that should be calibrated based on the new mix design or different using fibre type is general compressive strength $\left(f_{\mathrm{c}, \mathrm{i}}^{\prime}\right.$ and $\left.f_{\mathrm{c}, \mathrm{ii}}^{\prime}\right)$ for cube, cylinder specimens and general tensile $\operatorname{strength}\left(f_{\mathrm{ct}, \mathrm{i}}\right)$ 


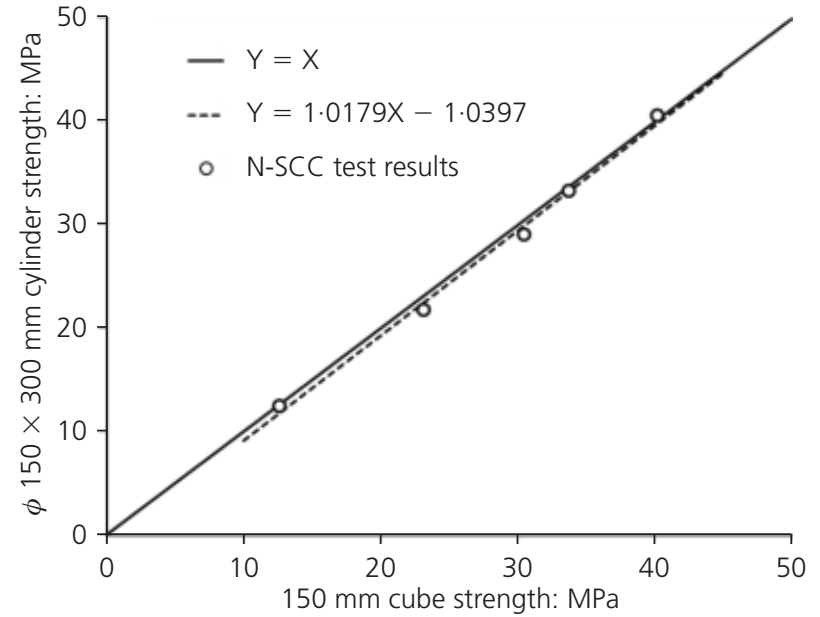

(a)

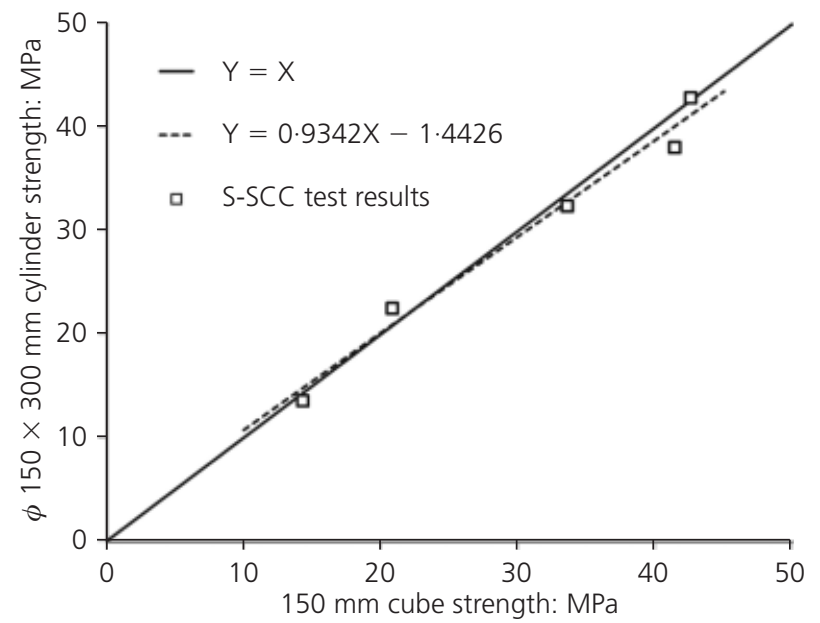

(c)

Figure 8. Relationship between compressive strengths of the $150 \times 300 \mathrm{~mm}$ cylinder and the $150 \mathrm{~mm}$ cube. (a) N-SCC,

(b) D-SCC, (c) S-SCC and (d) DS-SCC

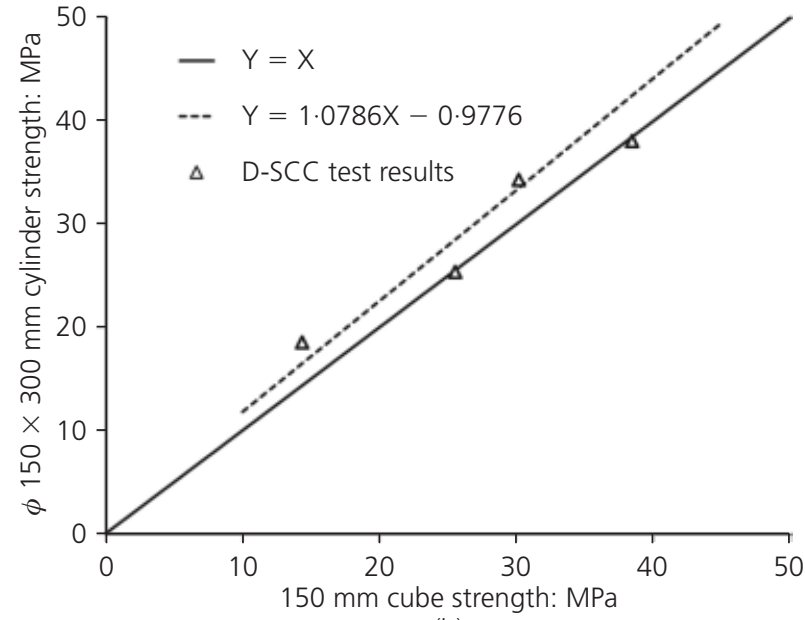

(b)

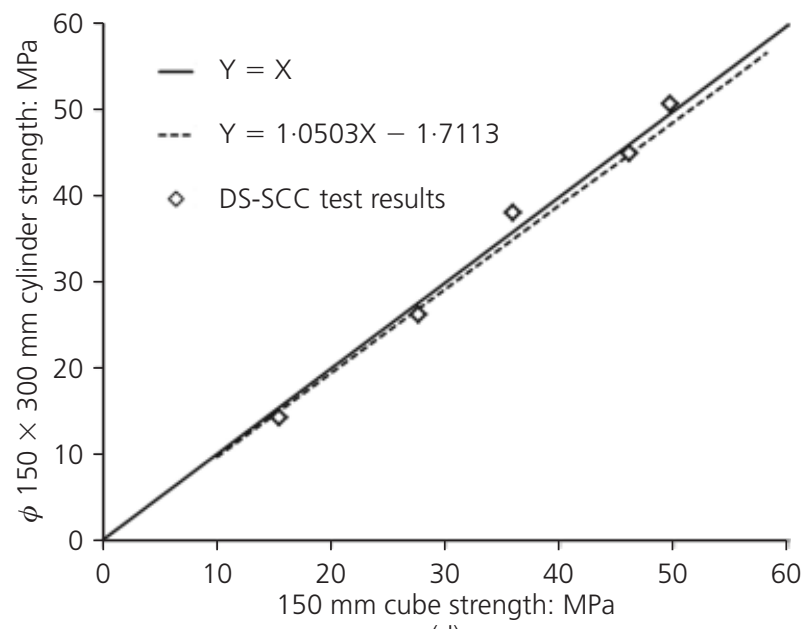

(d) for cylinder specimens. By calibrating this parameter the presented relationships and results in this study are useful for variable SCC investigations.

\section{REFERENCES}

ACI (American Concrete Institute) (2007) ACI 237R-07.

Self-consolidating concrete. ACI Committee 237. ACI, Farmington Hills, MI, USA.

Aïtcin PC, Miao B, Cook WD and Mitchell D (1994) Effects of size and curing on cylinder compressive strength of normal and high strength concretes. ACI Materials Journal 91(4): 349-354.

Aslani F and Nejadi S (2012a) Mechanical properties of conventional and self-compacting concrete: An analytical study. Construction Building Materials 36: 330-347.

Aslani F and Nejadi S (2012b) Bond characteristics of steel fibre reinforced self-compacting concrete. Canadian Journal of Civil Engineering 39(7): 834-848.

Aslani F and Nejadi S (2012c) Bond behavior of reinforcement in conventional and self-compacting concrete. Advances in Structural Engineering 15(12): 2033-2051.

Aslani F and Nejadi S (2012d) Shrinkage behavior of selfcompacting concrete. Journal of Zhejiang University Science A 13(6): 407-419.

Aslani F and Nejadi S (2012e) Bond characteristics of steel fiber and deformed reinforcing steel bar embedded in steel fiber reinforced self-compacting concrete (SFRSCC). Central European Journal of Engineering 2(3): 445-470.

ASTM (2000) ASTM Standards 2000. Concrete and Aggregates. ASTM International, West Conshohocken, PA, USA.

Bazant ZP (1984) Size effect in blunt fracture; concrete, rock, metal. Journal of Engineering Mechanics ASCE 110(4): 518535 . 
Bazant ZP (1987) Fracture energy of heterogeneous material and similitude. Proceedings of SEM-RILEM International Conference on Fracture of Concrete and Rock, Houston, TX, USA, pp. 390-402.

Bazant ZP (1993) Size effect in tensile and compressive quasibrittle failures. Proceedings of JCI International Workshop on Size Effect in Concrete Structures, Sendai, Japan, pp. 141-160.

Bazant ZP and Xiang Y (1997) Size effect in compression fracture: splitting crack band propagation. Journal of Engineering Mechanics ASCE 123(2): 162-172.

Carrasquillo RL, Nilson AH and Slate FO (1981) Properties of high strength concrete subject to short-term loads. $A C I$ Materials Journal 78(3): 171-178.

CEB-FIP (Comite Euro-International du Beton-Fédération Internationale de la Précontrainte) (1993) Model Code 1990. Bulletin D'Information No. 203/205. Comité EuroInternational du Béton (CEB), Lausanne, Switzerland.

Chin MS, Mansur MA and Wee TH (1997) Effects of shape, size and casting direction of specimens on stress-strain curves of high strength concrete. ACI Materials Journal 94(3): 209-219.

Date CG and Schnormeier R (1981) Development and use of 48 inch concrete cylinders in Arizona. Concrete International: Design and Construction 3(7): 42-45.

Day RL and Haque MN (1993) Correlation between strength of small and standard concrete cylinders. ACI Materials Journal 90(5): 452-462.

EFNARC (2005) The European Guidelines for Self-Compacting Concrete, Specification, Production and Use. EFNARC, Farnham, UK.

Khayat KH and Roussel Y (1999) Testing and performance of fiber-reinforced, self-consolidating concrete. Proceedings of Symposium on Self-Compacting Concrete, Stockholm, Sweden (Skarendahl AP (ed.)), pp. 509-521.

Kim JK and Eo SH (1990) Size effect in concrete specimens with dissimilar initial cracks. Magazine of Concrete Research 42(153): 233-238.

Kim JK, Yi ST, Park CK and Eo SH (1999) Size effect on compressive strength of plain and spirally reinforced concrete cylinders. ACI Structural Journal 96(1): 88-94.

Kim JK, Yi ST and Yang EI (2000) Size effect on flexural compressive strength of concrete specimens. ACI Structural Journal 97(2): 291-296.

Kim JK, Yi ST and Kim JHJ (2001) Effect of specimen sizes on flexural compressive strength of concrete. ACI Structural
Journal 98(3): 416-424.

Lessard M, Chaallal O and Aïtcin PC (1993) Testing high strength concrete compressive strength. ACI Materials Journal 90(4): 303-308.

Malhotra JM (1976) Are 48 inch concrete cylinders as good as 612 inch cylinders for quality control of concrete. $A C I$ Materials Journal 73(14): 333-336.

Moreno J (1990) The state of the art of high-strength concrete in Chicago - 225W. Wacker Drive. Concrete International: Design Construction 12(1): 35-39.

Nasser KW and Kenyon JC (1984) Why not 36 inch cylinders for testing concrete compressive strength. ACI Materials Journal 81(1): 47-53.

Neville AM (1995) Properties of Concrete. Longman, UK.

Okamura H (1997) Self-compacting high-performance concrete. Concrete International 19(7): 50-54.

RTA (Regional Transportation Authority) (2006) Materials Test Methods, vol. 1. RTA, Chicago, IL, USA.

SA (Standards Australia) (1998) AS 3583. Methods of test for supplementary cementitious materials for use with portland cement. Standards Australia, Sydney, Australia.

SA (2000) AS 1478.1. Chemical admixtures for concrete, mortar and grout - admixtures for concrete. Standards Australia, Sydney, Australia.

SA (2001) AS 3582.2. Supplementary cementitious materials for use with portland and blended cement - Slag - Ground granulated iron blast-furnace. Standards Australia, Sydney, Australia.

SA (2006) AS 2350. Methods of testing portland and blended cements. Standards Australia.

SA (2010) AS 3972. General purpose and blended cements. Standards Australia, Sydney, Australia.

SA (2011) AS 1141. Methods for sampling and testing aggregates. Particle size distribution - sieving method. Standards Australia, Sydney, Australia.

Sleiman Al, Islam MS, Issa MA, Yousif AA and Issa MA (2000) Specimen and aggregate size effect on concrete compressive strength. Cement and Concrete Aggregates 22(2): 103-115.

Tokyay M and Özdemir S (1997) Specimen shape and size effect on the compressive strength of higher strength concrete. Cement and Concrete Research 27(8): 1281-1289.

Yi ST, Yang El and Choi JC (2006) Effect of specimen sizes, specimen shapes, and placement directions on compressive strength of concrete. Nuclear Engineering and Design 236(2): $115-127$.

\section{WHAT DO YOU THINK?}

To discuss this paper, please submit up to 500 words to the editor at www.editorialmanager.com/macr by 1 February 2014. Your contribution will be forwarded to the author(s) for a reply and, if considered appropriate by the editorial panel, will be published as a discussion in a future issue of the journal. 